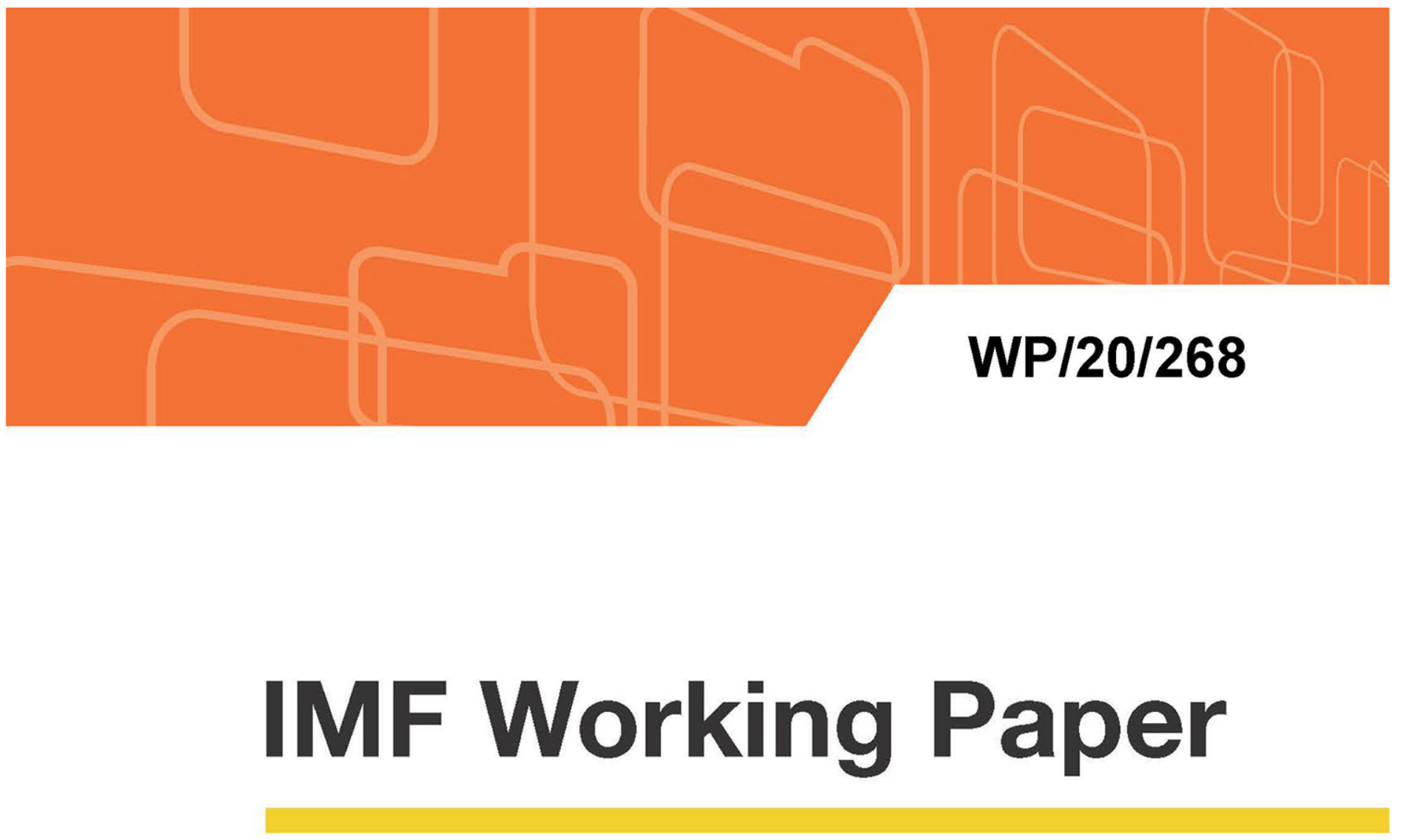

\title{
Reconsidering Climate Mitigation Policy in the UK
}

by Nicolas Arregui and lan Parry

IMF Working Papers describe research in progress by the author(s) and are published to elicit comments and to encourage debate. The views expressed in IMF Working Papers are those of the author(s) and do not necessarily represent the views of the IMF, its Executive Board, or IMF management. 


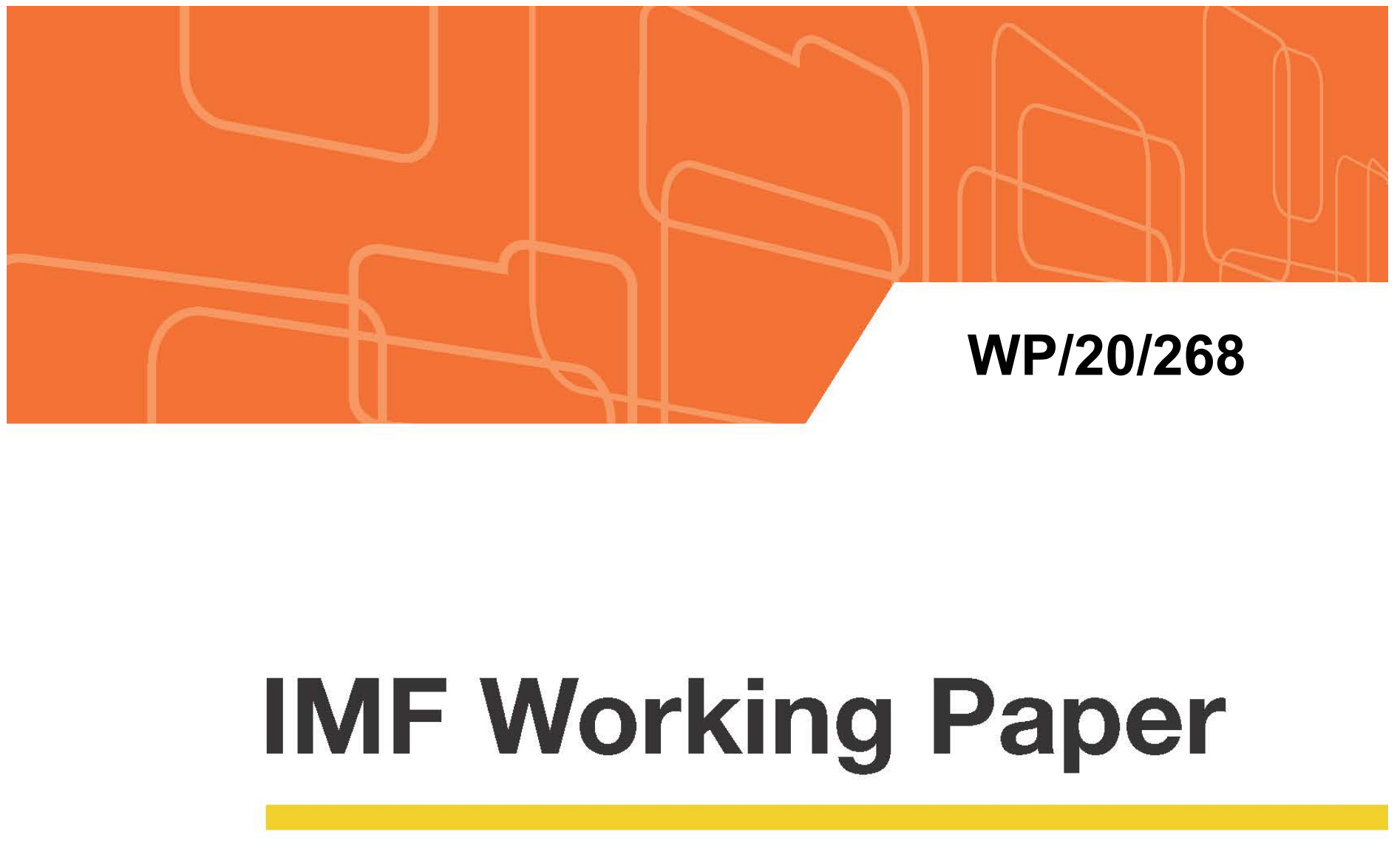

\section{Reconsidering Climate Mitigation Policy in the UK}

by Nicolas Arregui and lan Parry

IMF Working Papers describe research in progress by the author(s) and are published to elicit comments and to encourage debate. The views expressed in IMF Working Papers are those of the author(s) and do not necessarily represent the views of the IMF, its Executive Board, or IMF management. 


\title{
IMF Working Paper
}

\author{
European Department
}

\section{Reconsidering Climate Mitigation Policy in the UK \\ Prepared by Nicolas Arregui and Ian Parry ${ }^{1}$}

Authorized for distribution by Dora Iakova

December 2020

\section{IMF Working Papers describe research in progress by the author(s) and are published to elicit comments and to encourage debate. The views expressed in IMF Working Papers are those of the author(s) and do not necessarily represent the views of the IMF, its Executive Board, or IMF management.}

\begin{abstract}
The UK has pledged to cut greenhouse gases 57 percent below 1990 levels by 2030, to be emisisons neutral by 2050, and to phase out internal combustion engine vehicles by 2030 . Much progress has been made, but fully achieving these ambitious objectives with the current policy framework will be challenging as it involves multiple and overlapping pricing schemes with significant sectoral differences in carbon prices and may be difficult to scale up on political and administrative grounds. This paper discusses an alternative framework consisting of: (i) a comprehensive carbon price (ideally a tax) rising to at least $£ 60$ (US \$75) per ton by 2030; and (ii) reinforcing sectoral policies, most importantly feebates for the transport, industrial, and building sectors. This framework could implement mitigation targets, while limiting burdens on households and firms to enhance acceptability, and still raise revenues of 0.8 percent of GDP in 2030. The UK could also leverage its COP26 presidency to promote dialogue on international carbon price floors and pricing of international transport emissions.
\end{abstract}

JEL Classification Numbers: Q48, Q54, Q58, H23

Keywords: Climate change, net-zero, UK climate mitigation, carbon pricing, feebate, international carbon price floor.

Author's E-Mail Address: narregui@,imf.org, iparry@,imf.org

\footnotetext{
${ }^{1}$ We are grateful to Simon Black, Dora Iakova and James Roaf for comments and suggestions. Khamal Clayton and Victor Mylonas provided valuable research assistance, and Ben Park and Rachelle Vega provided excellent production assistance.
} 


\section{CONTENTS}

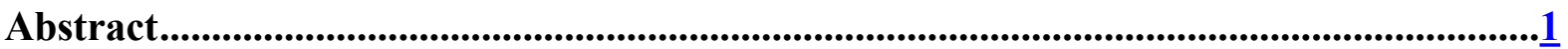

I.INTRODUCTION ............................................................................................................................

II. BACKGROUND ON MITIGATION OBJECTIVES, EMISSIONS TRENDS, AND

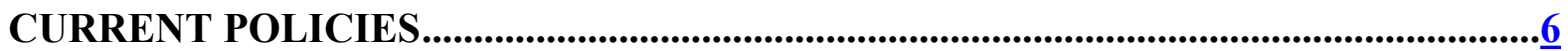

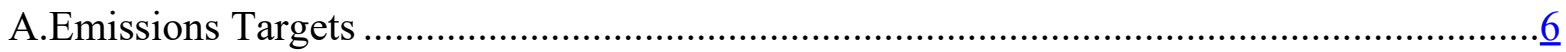

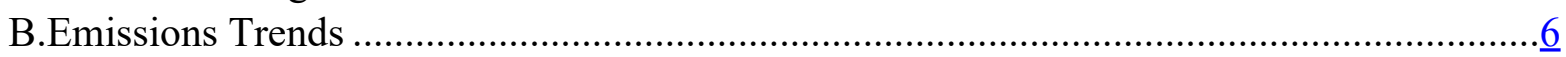

C.Current Policy Framework and Obstacles to Scaling it Up .............................................10

III.ASSESSING UK CLIMATE POLICY OPTIONS POST-BREXIT ...........................15

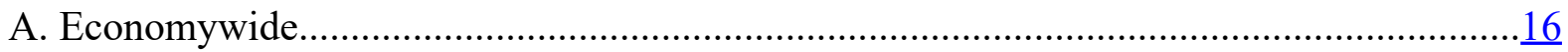

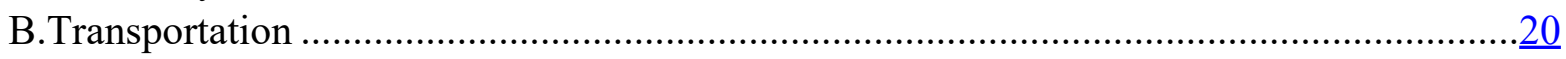

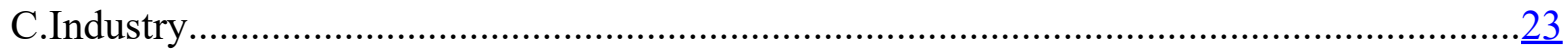

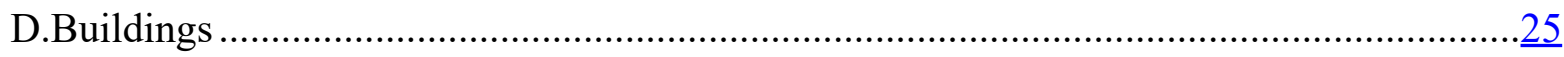

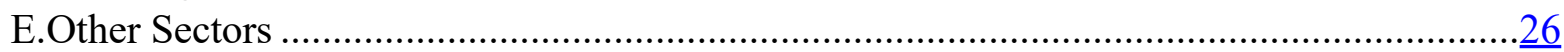

IV.INTERNATIONAL PRICING SCHEMES ........................................................................

V.SUMMING UP ......................................................................................................................

\section{BOXES}

1.Broader Reforms to the Pricing of Road Transport ..........................................................22

2.The Burden on Industry from Carbon Pricing and Feebates ………………………........

3. Illustrative Impacts of Carbon Pricing and Feebates on Production Costs for Steel and

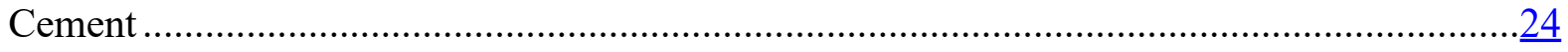

\section{FIGURES}

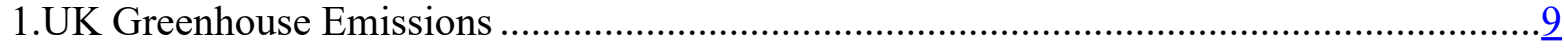

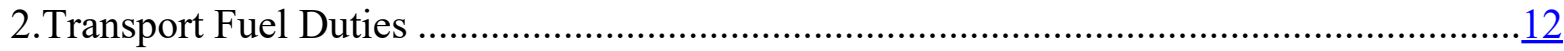

3.Domestic Energy Use and Prices ...................................................................................

ANNEX

I.FURTHER DISTRIBUTIONAL ANALYSIS ...............................................................

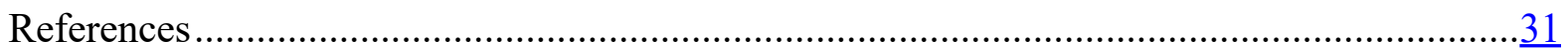




\section{INTRODUCTION}

The public health and economic crisis precipitated by the COVID-19 pandemic has not altered the global need for rapidly transitioning to zero carbon energy systems. A global emissions pathway consistent with limiting future global warming to $1.5^{\circ}-2^{\circ} \mathrm{C}$ above preindustrial levels - the central objective of the 2015 Paris Agreement-would require cutting global fossil fuel carbon dioxide $\left(\mathrm{CO}_{2}\right)$ and other greenhouse gases (GHGs) by 25-50 percent below 2018 levels by 2030, with progressively deeper emissions reductions thereafter. ${ }^{1}$ Global $\mathrm{CO}_{2}$ emissions in 2020 are projected to be about 8 percent lower than in 2019 , due to both lower GDP and structural shifts in the economy (e.g., more remote working), but emissions are likely to start rising again in 2021 as economies recover and some of the structural shifts are partially reversed. With governments likely to bring forward investment plans to help boost their economies, the pandemic has added to the urgency of ensuring that this new investment is appropriately allocated to low-carbon technologies. A key instrument for achieving this - carbon pricing — also generates new revenue at a time of heightened fiscal pressures resulting from the crisis.

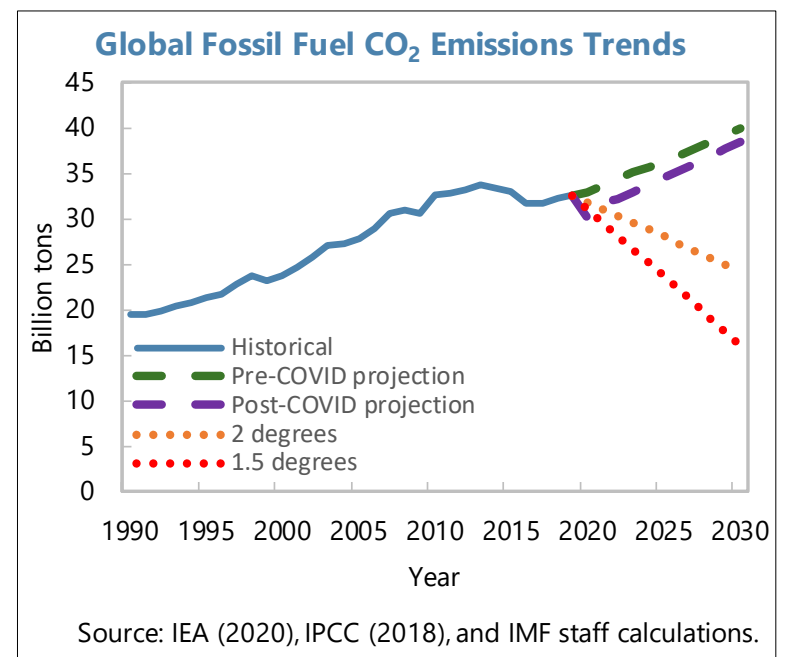

At a global level, current mitigation pledges for the 2015 Paris Agreement fall well short of temperature stabilization goals. Even if fully implemented, pledges by 190 parties would cut global emissions in 2030 by about one third of the emissions reductions consistent with the $2^{\circ} \mathrm{C}$ target (let alone the $1.5^{\circ} \mathrm{C}$ target), ${ }^{2}$ the principal reason for this shortfall is that mitigation possibilities in large emitting emerging market economies are not optimally exploited from a global perspective (see below), in part reflecting their differentiated responsibilities. ${ }^{3}$ Parties are required to submit revised climate strategies ahead of the pivotal climate meeting, COP 26 in Glasgow in 2021, which are expected to have enhanced mitigation ambition. Meeting temperature stabilization goals will likely require an additional international mechanism to complement the Paris process-IMF staff have proposed a carbon price floor arrangement among large emitters. ${ }^{4}$

\section{Climate change poses highly uncertain macroeconomic risks at the global and national} level. By 2100 studies suggest warming could be permanently lowering global GDP by anything from 5 to 25 percent below GDP levels with no climate change (reflecting, for example, rising

\footnotetext{
${ }^{1} \mathrm{Net}$ GHG emissions need to decline to zero by 2050 for the $1.5^{\circ} \mathrm{C}$ target or by 2070 for the $2^{\circ} \mathrm{C}$ target (IPCC 2018).

${ }^{2}$ IMF (2019a), UNEP (2019).

${ }^{3}$ Due, for example, to their lower per capita income (UN 1992, Article 3.1).

${ }^{4}$ IMF (2019a).
} 
sea levels, reduced crop yields, more frequent and extreme weather events, non-market impacts). ${ }^{5}$ The overriding concern however are tail risks (e.g., runaway warming from release of underground methane, collapsing ice sheets) that are difficult to incorporate in these estimates. ${ }^{6}$ The World Economic Forum ${ }^{7}$ ranks climate change as the greatest threat to the planet. There are also risks on the transition side as economies are restructured to eliminate emissions from use of fossil fuels and other sources. ${ }^{8}$

\section{A thorough reconsideration of mitigation policy is especially timely for the $U K$ with the} end of the Brexit transition period. UK GHG emissions have fallen substantially in the last decade but going forward projected emissions exceed levels consistent with the fourth (2023-2027) and fifth (2028-2032) carbon budgets, even in the context of COVID. ${ }^{9}$ In addition, these budgets are not stringent enough to be consistent with the recently adopted net zero by 2050 commitment. However, Brexit offers the opportunity to rationalize and simplify the pricing of power and industrial sector emissions which are currently covered by the EU Emissions Trading System (ETS) and multiple domestic pricing mechanisms. ${ }^{10}$ The existing policy framework is not well suited to deep decarbonization of transportation, industry, and buildings, as it does not provide sufficiently powerful, but also politically acceptable, mitigation incentives. As president of the pivotal COP26 UN climate meeting, the UK also has an opportunity to promote dialogue on international carbon pricing mechanisms.

\section{This paper discusses an alternative domestic mitigation framework for the UK consisting of a uniform carbon pricing scheme reinforced with powerful measures at the sectoral} level. ${ }^{11}$ The uniform carbon price would cover all energy and industrial sources of $\mathrm{CO}_{2}$, ideally with a price rising steadily from current levels to at least $£ 60$ (US \$75) per ton by $2030\left(\mathrm{CO}_{2}\right.$ prices in the power and industrial sector are currently about $£ 40$ per ton, so would rise by a further $£ 20$ per ton, but prices are modest or zero for other sectors). ${ }^{12}$ Ideally, this instrument would take the form of a carbon tax which: (i) promotes the full range of mitigation opportunities; (ii) provides the certainty over emissions prices needed to promote clean

\footnotetext{
${ }^{5}$ See Nordhaus (2018) and Burke and others (2015). Impact assessments remain highly contentious, for example, damage to the natural world, mass migration, international conflict and non-linear climate change are very difficult to quantify.

${ }^{6}$ Lenton and others (2019), Weitzman (2011).

${ }^{7}$ WEF (2019).

${ }^{8}$ For example, Batten (2018).

${ }^{9}$ In November 2020, the UK government announced a 10-point vision plan laying measures to scale up the country's climate ambition. Measures include a ban by 2030 on the sale of new petrol and diesel vehicles, a target to quadruple offshore wind energy generation to $40 \mathrm{GW}$ by 2030 , and new funding to cut emissions in various areas, including public funds for nuclear power, electric vehicle charging infrastructure, energy efficiency improvements in homes and public buildings, carbon capture and storage, nature restauration, and R\&D support for hard-todecarbonize industries. Further details on implications for carbon pricing, regulations, and a detailed road map for implementation are still to be released.

${ }^{10}$ See Chen and others (2020) for a discussion on achieving more robust carbon pricing within the EU framework.

${ }^{11}$ ZCC (2020) discusses a similar policy framework for the UK, though with somewhat less emphasis on reinforcing fiscal measures at the sectoral level.

${ }^{12}$ All prices are expressed in year 2018 pound sterling (or thereabouts).
} 
technology investment; (iii) provides a direct and robust source of revenue for the Treasury; (iv) allows reinforcing measures to reduce emissions; and (v) reforms the current set of pricing schemes that disproportionately burdens the power sector. A domestic ETS, which the UK government currently favors, can largely mimic the advantages of a tax, if it is combined with a robust price floor and full allowance auctions. While comprehensive and predictable carbon pricing would be key to ensuring that activities and investments shift to exploit the lowest cost abatement options, complementary sectoral policies are essential. First, they can help address sector-specific factors which hinder emission reductions, including financing constraints and incomplete markets. ${ }^{13}$ Second, and the main emphasis here, they can play a reinforcing role when carbon pricing is subject to acceptability constraints. Third, they may be needed to meet sectoral targets that are more ambitious than nationwide targets.

Feebates are a promising reinforcing instrument. Feebates provide a (revenue-neutral) sliding scale of fees on products or activities with above average emission rates and a sliding scale of rebates for products or activities with below average emission rates. They can provide strong incentives to reduce emissions intensity without (unlike fuel taxes or carbon pricing) a politically challenging first-order tax burden on households and firms and (unlike subsidies for clean technologies) a revenue loss for the government. They are a particularly attractive instrument for promoting the progressive phase out of internal combustion engine (ICE) vehicles but they could also strengthen de-carbonization incentives in industry while (unlike a higher carbon price) largely avoiding pressure for a border carbon adjustment (BCA) or other compensation mechanisms. Variants of feebates could also promote adoption of clean heating systems in buildings and reductions in agricultural emissions. ${ }^{14}$

As President of COP 26, the UK might promote dialogue on an international carbon price floor and pricing of fuels used for international transportation fuels. The UK cannot stop global warming on its own. Global coordination will be needed. A price floor should complement the Paris Agreement, cover large emitters, impose stricter requirements on advanced countries, and allow flexibility at the national level (e.g., in exceptional cases, policies that have equivalent emissions outcomes as price floors). Pricing is also needed for international maritime and aviation emissions, both for upfront funding of clean technology development and to establish the price signal needed for deploying them, though creative designs may be necessary to create powerful, but also acceptable, schemes.

The rest of the paper contains three main sections. The first provides background on UK emissions objectives, trends, and current mitigation policies. The second discusses an alternative policy framework with comprehensive pricing reinforced by sectoral measures. And the third briefly covers international pricing schemes.

\footnotetext{
${ }^{13}$ See Arregui and others 2020.

${ }^{14}$ Absent frictions other than the climate externality, feebates are less efficient that carbon pricing as they do not promote the same demand response (e.g., reductions in vehicle use) but they are more flexible and cost-effective than regulations.
} 


\section{BACKground On Mitigation ObJectives, Emissions Trends, AND CURRENT Policies}

\section{A. Emissions Targets}

The UK pioneered the statutory underpinning of emissions target-setting. The government is required to set, twelve years in advance, five-yearly carbon budgets out to 2050, with the Committee on Climate Change (CCC) reporting to Parliament annual progress on meeting these budgets.

The UK recently strengthened its intermediate and long-range emissions targets. As part of the EU, the UK committed to reducing EU GHGs 40 percent below 1990 levels by 2030 for the 2015 Paris Agreement. In 2019 however, the UK amended the Climate Change Act by pledging to cut emissions 57 percent below 1990 levels by 2030 and introducing a net-zero GHG emissions target for 2050 (becoming the first major world economy to set a legally binding netzero target). In line with other advanced economies, a faster pace (compared to the global average) in emission reductions might be rationalized by the UK's economic development level, its large contribution to historical emissions, and the significant carbon footprint in its imports.

\section{Supplementary sectoral targets are designed to support progress on meeting emissions} goals. Most notably, the UK plans to ban the sale of new gasoline, diesel, hybrid, and plug-in electric hybrid cars and vans by 2030 - only electric vehicles (EVs) and hydrogen (or alternative) vehicles will be allowed. ${ }^{15}$ In addition, coal generation plants (without carbon capture and storage) will be phased out by 2025.

\section{B. Emissions Trends}

The UK has made substantial progress in reducing economywide GHGs, principally due to progress in power generation (Figure 1).

- The UK's reduction of total GHG emissions - now 42 percent lower than in 1990 - is large compared with other OECD countries. Emissions per capita started at 25 percent above the level for European OECD countries and is now about ten percent below it.

- Two-thirds of the GHG reduction came from reductions in $\mathrm{CO}_{2}$ emissions reflecting marketled developments and concerted policy efforts that promoted energy efficiency, a shift from coal to gas in power generation, and a broader shift to less energy-intensive UK industry. ${ }^{16}$ Reductions in methane emissions (primarily from agriculture, coal mining and handling, gas

\footnotetext{
${ }^{15}$ An estimated 2.5 million charging stations will be needed to accommodate EVs by 2035 (currently there are 11,000 charging stations). EVs are currently less than 1 percent of the on-road vehicle fleet but sales have accelerated in recent years (CCC 2020).

${ }^{16}$ The UK economy is less energy intensive than average in the OECD, due to a low share of industry and a high share of services in output. The share of renewables in total primary energy supply remains below the OECD average however, despite rapid growth since 2007 (OECD 2017).
} 
extraction and distribution, and waste management) account for a further quarter of the total GHG reduction, though these emissions have been broadly flat since $2013 .^{17}$

- GHG emissions reductions, particularly over the last decade, have been largely concentrated in the power sector. Concerted efforts to decarbonize the power sector are the best demonstration of policy impact. ${ }^{18}$ While progress has been significant, the sector typically poses a simpler challenge for policy. Power is an aggregated sector, involving relatively few commercial players, with centralized UK regulatory tools.

- Progress in sectors other than power has effectively stalled in the last five years. For instance, transport sector emissions (which accounts for about 27 percent of total GHGs) has made virtually no contribution to reducing GHG emissions since 1990 and has indeed increased by about five percent since 2013 .

The reduction in consumption-based GHG emissions is less flattering. The standard accounting of production GHGs excludes $\mathrm{CO}_{2}$ generated when making goods that are imported into the UK (minus that of exports) and the UK's share of international aviation and shipping.

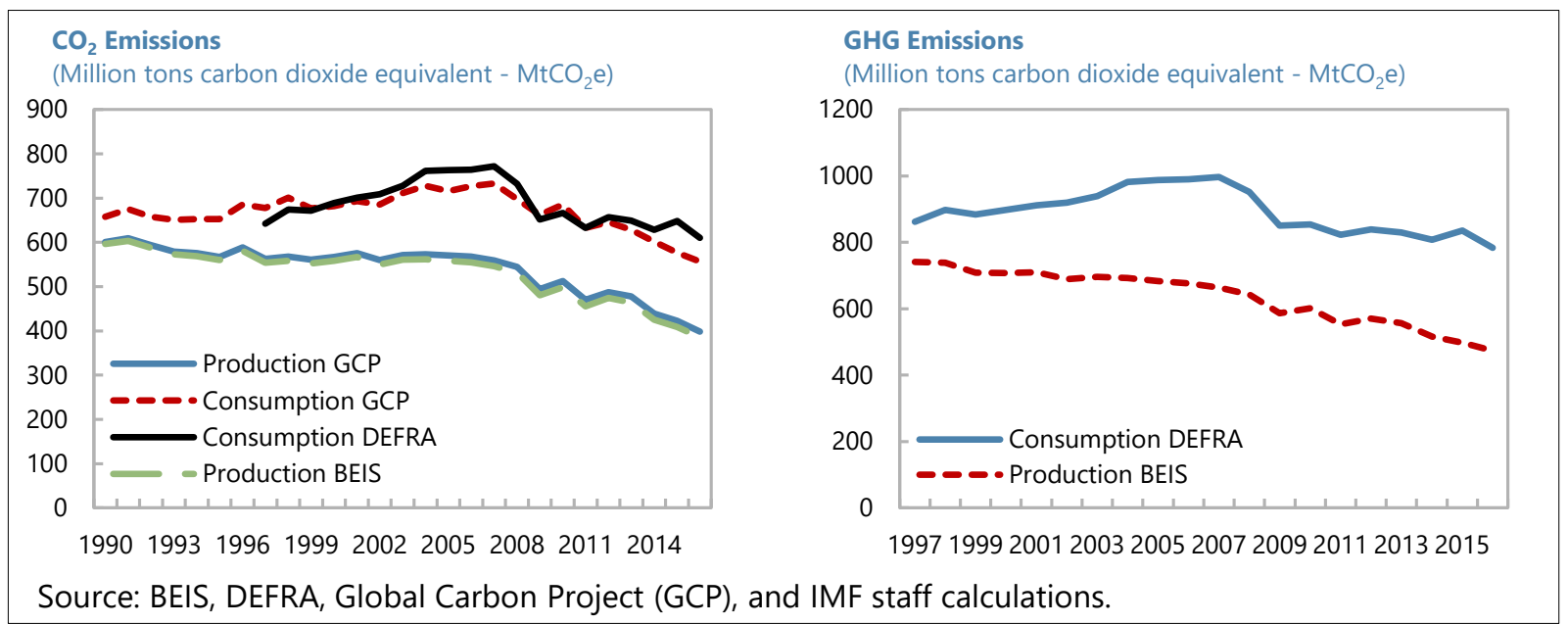

The UK's imports have more embodied $\mathrm{CO}_{2}$ than exports so consumption-based $\mathrm{CO}_{2}$ emissions exceed production-based emissions (OECD 2017). ${ }^{19}$ While consumption-based GHG emissions fell by around 10 percent from 1997 to 2016, this is well short of the 36 percent drop in production-based emissions. As suggested by CCC $(2017,2019)$, the government should

\footnotetext{
${ }^{17}$ The remaining ten percent of the reduction is accounted for mostly by lower nitrous oxide emissions related to the production of nitric and adipic acids.

${ }^{18}$ See CCC (2018). The privatization of electric companies was accompanied by reduced gas prices and improvements in electricity generation technology, which led to greater use of cleaner energy sources, especially gas, which replaced coal and oil. At the end of the 1990s, the 'dash for gas' and the impact of privatization lessened, and the UK began to implement a new set of climate-change policies directly targeted at energy efficiency and emission reductions (OECD 2011).

19 The UK has a similar consumption footprint to many European countries, with consumption footprint $\mathrm{CO}_{2}$ emissions per person greater than France, but lower than Germany (CCC 2019).
} 
continue to monitor consumption emissions to verify that reductions in production emissions are not offset by emissions leakage to other countries. ${ }^{20}$

Despite significant progress, the UK is not fully on track to meet future climate budgets, and these budgets are not aligned with (linear) emissions pathways for carbon neutrality. The UK met the first and second carbon budgets (2008-12 and 2013-17) and is on track to outperform the third (2018-22) budget. However, the CCC's 2018 and 2019 Progress Reports to

Parliament concluded the government's Clean Growth Strategy (CGS), launched in October 2017, lacks the policy specifics needed to achieve the fourth and fifth carbon budgets (covering 2023-27 and 2028-32, respectively) and called on the government to bring forward fully funded policies to meet

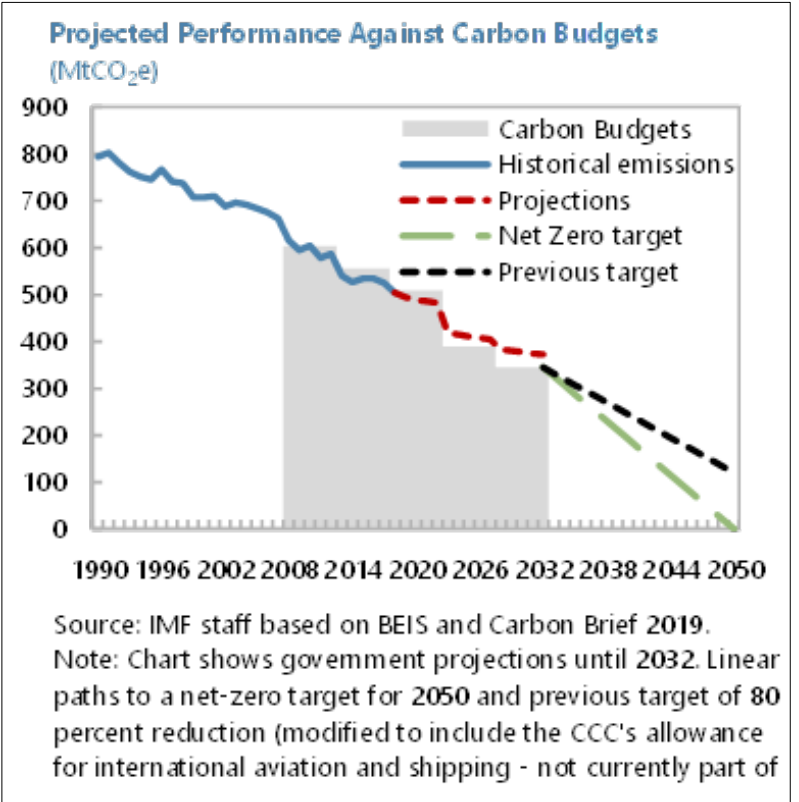
them. ${ }^{21}$ Moreover, these future carbon budgets are now too loose as they were set prior to the UK adopting the carbon neutrality goal for 2050. Clarifying future policies is urgent given the lead times needed to drive the necessary investments.

\footnotetext{
${ }^{20}$ Measuring consumption emissions is not straightforward however, as it requires estimates of emissions along international supply chains and there are no agreed international reporting standards. Emissions leakage would be less of a concern if countries were to meet their mitigation pledges for the Paris Agreement - in that case, leakage to other countries would need to be offset by stronger mitigation policies in those countries.

${ }^{21}$ The CGS outlines action up to 2032 and highlights possible emissions pathways to neutrality in 2050. It specifies sectoral targets (including those mentioned above, improving the energy productivity of business by at least 20 percent by 2030 , and working towards zero avoidable waste by 2050); emphasizes the need for private capital in sustainable projects; and includes public investment of $£ 2.5$ billion to support low-carbon innovation between 2015-2021.
} 


\section{Figure 1. UK Greenhouse Emissions}

UK Green House Gas Emissions

(Million tonnes carbon dioxide equivalent-MtCO2e)

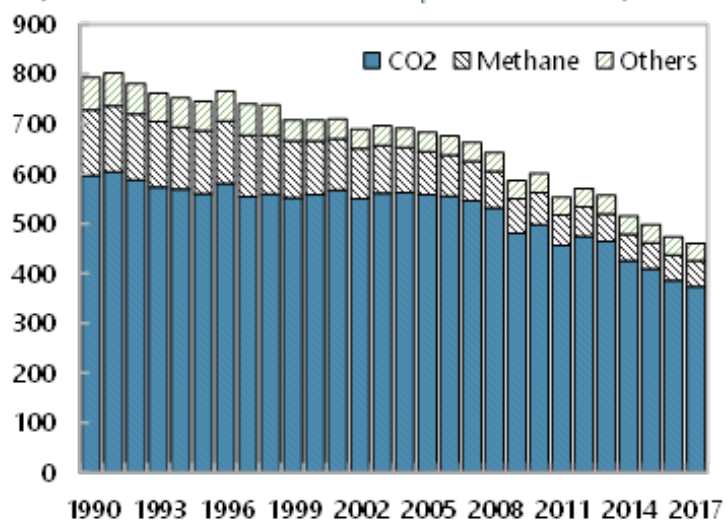

1990199319961999200220052008201120142017

Greenhouse Gass Emissions

(Percent change 1990-2016)

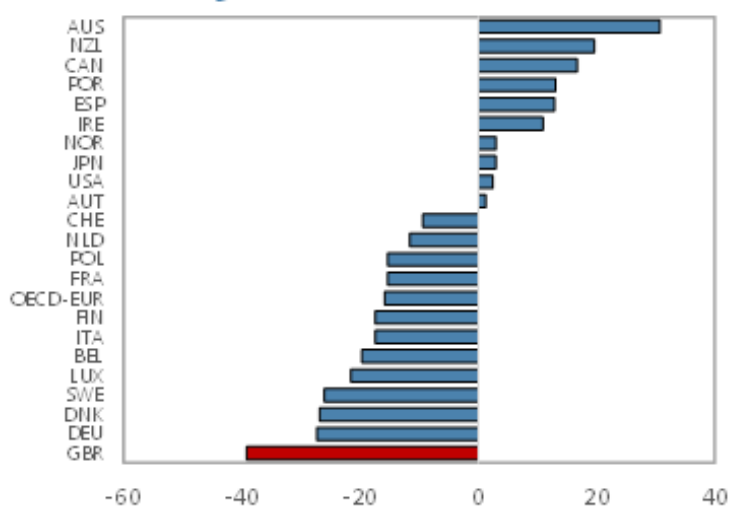

Enissions by Sector

(in percent of total; 2017)

- Power excl. Resid

Business/Industry

- Transport

- Residential Dir.

- Residential Indir.

- Agriaulture

$\square$ Other

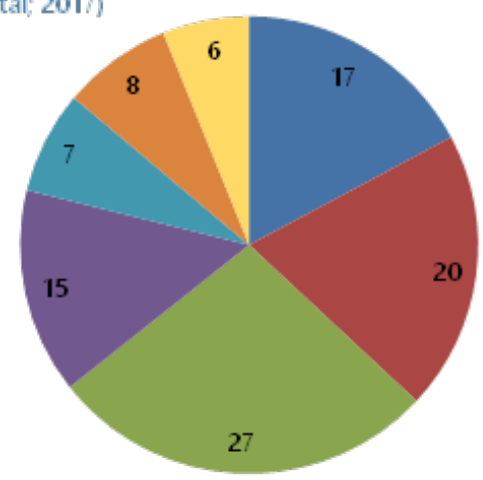

Source: BEIS, OECD, and IMF staff calculations.

Note: "Agriculture" includes land use, land-use change, and forestry. "Other" is the sum of public and waste.
Cumulative Change in Enissions

(Percent relative to 1990 level)

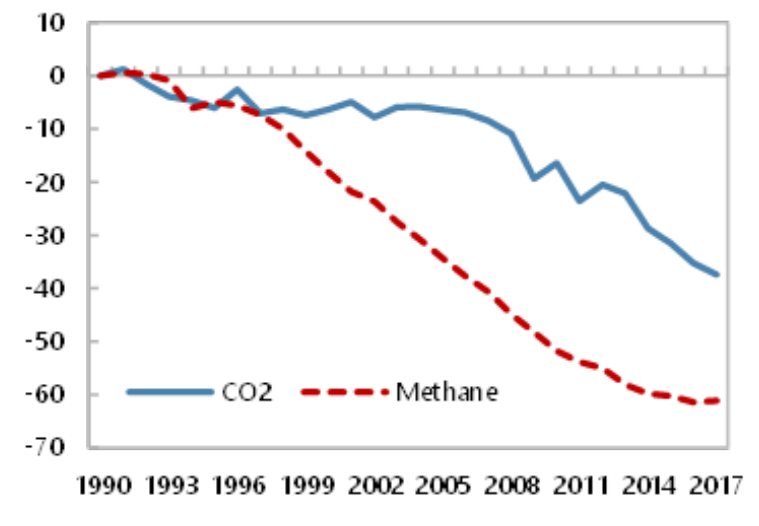

Greenhouse Gas Emission Intensity

(Tons per capita)

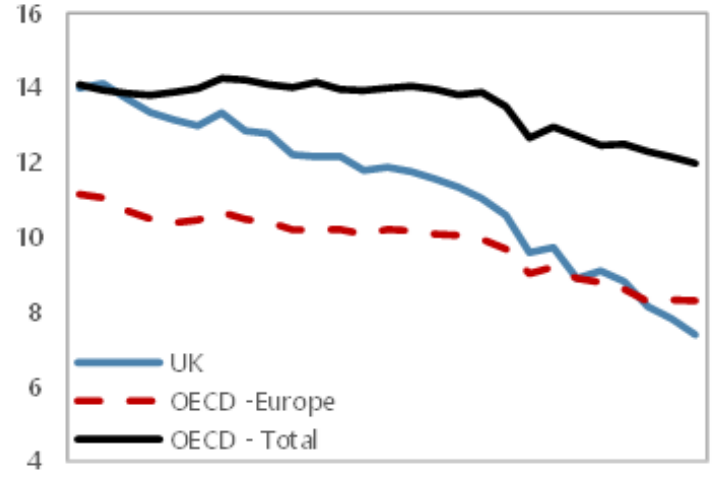

$\begin{array}{lllllllll}1990 & 1993 & 1996 & 1999 & 2002 & 2005 & 2008 & 2011 & 2014\end{array}$

Emissions Growth by Selected Sectors

(in percent)

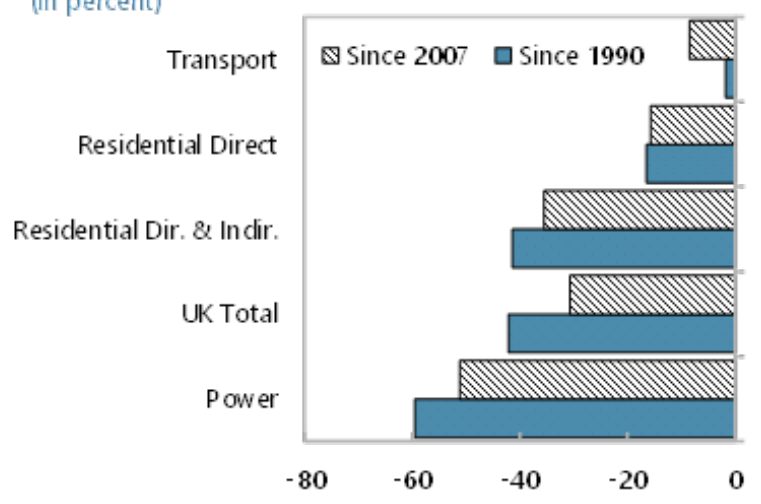

$\begin{array}{lllll}-80 & -60 & -40 & -20 & 0\end{array}$ 


\section{Current Policy Framework and Obstacles to Scaling it Up}

Multiple carbon pricing schemes form the basis of current UK mitigation policy. These include:

- The EU ETS covering emissions from power generation and large industrial firms - the $\mathrm{CO}_{2}$ allowance price is currently equivalent to $£ 27$ per ton. ${ }^{22}$

- The Carbon Price Floor (CPF), covering emissions from power generation, and imposing a national level variable tax, the Carbon Price Support (CPS), currently $£ 18$ per ton, set three years in advance and equal to the difference between the projected EU ETS price and the $\mathrm{CPF}^{23}$

- The Climate Change Levy (CCL) which imposes taxes on energy consumed by firms (but not households and vehicles) — current rates are 0.811 pence per kilo-watthour $(\mathrm{kWh})$ for electricity, 0.406 pence per $\mathrm{kWh}$ for natural gas, and 2.175 pence per $\mathrm{kg}$ for LPG. The CCL does not account for the carbon content of electricity versus natural gas and is currently equivalent to about $£ 25$ per ton of $\mathrm{CO}_{2}$ for electricity and $£ 20$ per ton for gas. ${ }^{24}$

- Mechanisms for funding subsidy outlays on zero emission technologies through higher generation prices.

Transportation emissions are affected by three overlapping policies. These include:

- Vehicle excise duties (VEDs) which, for the first year, consist of: (i) a fixed charge of $£ 140$ for all non-EVs; and (ii) charges varying from $£ 0$ for EVs to $£ 2,000$ across 13 vehicle classifications. The new fleet average (fixed plus variable) excise was $£ 317$ in 2019 . ${ }^{25}$

- EU $\mathrm{CO}_{2}$ emission rate standards for average new vehicle fleets - the 2021 target, set at the EU level, is 95 grams $(\mathrm{g}) \mathrm{CO}_{2}$ per km, falling to about $60 \mathrm{~g}$ per $\mathrm{km}$ in 2030.

- Fuel excise taxes, currently 58 pence per liter for both gasoline and diesel, equivalent to carbon taxes of $£ 246$ per ton of $\mathrm{CO}_{2}$ for gasoline and $£ 213$ per ton for diesel (though these taxes largely reflect other, non-carbon externalities - see below).

The current policy framework is excessively costly for a given total emissions reduction. Minimizing mitigation costs requires a uniform carbon price to equate the cost of the last ton

\footnotetext{
${ }^{22}$ See https://ember-climate.org/carbon-price-viewer.

${ }^{23}$ See Hirst (2018).

${ }^{24}$ Based on the emission factors in DBEIS (2018). Starting in 2019, CCL rates will be rebalanced between energy sources, gradually moving from a ratio of 2.9: 1 (electricity: gas) in 2018 to parity in 2025 . This rebalancing will reduce the CCL carbon distortion between electricity and gas, but it will not equalize the CCL on an effective carbon basis. The specific rate at which parity will be attained is yet to be announced.

${ }^{25}$ The VED payment is flat in subsequent years at a level unrelated to $\mathrm{CO}_{2}$ emissions for petrol or diesel vehicles, while payments are lower for electric and alternative fuel vehicles.
} 
best) efficient and prevailing fuel prices; ${ }^{31}$ and (ii) forgone cumulative revenues of over $£ 46$ billion since 2011 . $^{32}$

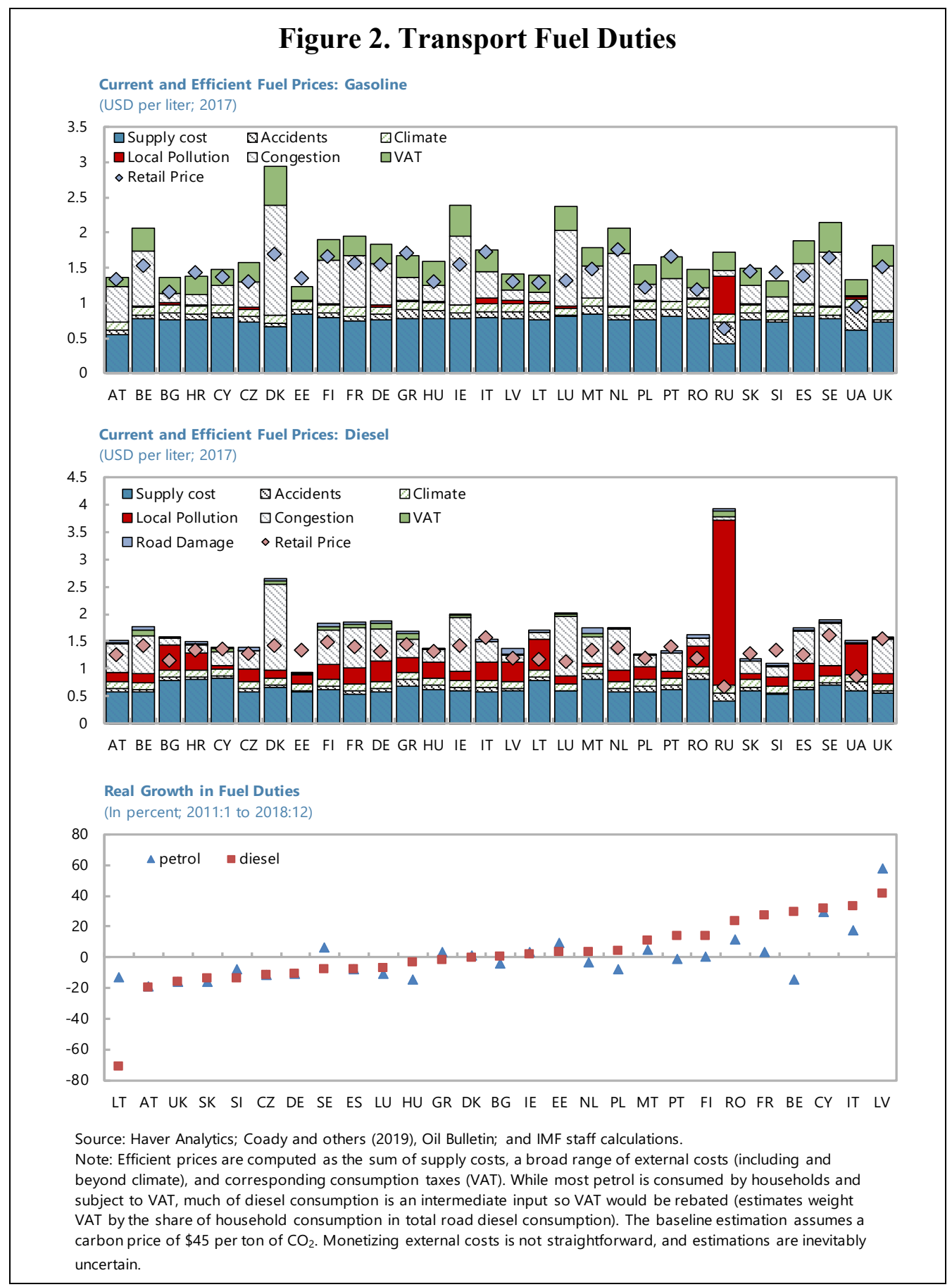

\footnotetext{
${ }^{31}$ Begh and Haigh (2018) estimate that traffic (i.e., kms driven) has increased by four percent due to the freeze. ${ }^{32}$ While the government's stated policy is that "all duties continue to be uprated in line with inflation," continued fuel duty freezes have been deemed a "near certainty" (OBR 2017). Holding down fuel prices is a highly inefficient way to help low-income households as most of the benefits leak away to the non-poor.
} 


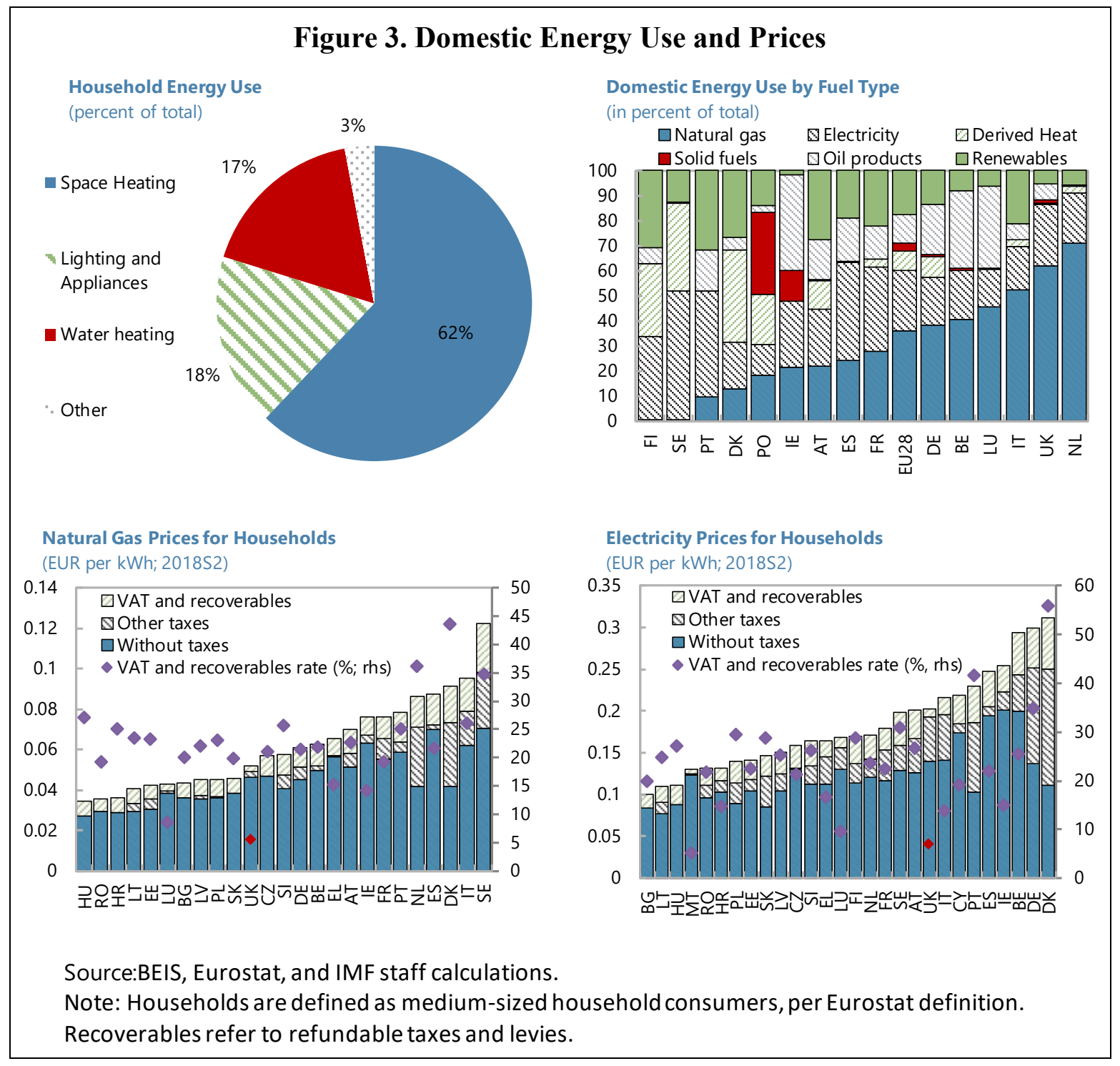

\section{Existing carbon pricing policies are likely difficult to scale up on both political acceptability and administrative grounds.}

- Acceptability. Current policies impose a first-order tax burden (see Box 1 below) which for most sectors is largely passed forward to consumers, except in trade-exposed industries where the burden may be largely borne by producers. Potential opposition from adversely affected groups may constrain carbon pricing - for example, total carbon prices were due to rise every year until 2020 but this was subsequently scaled back (via freezing the CPS) to limit burdens on households and firms. The problem may be a little overstated however, for example, an additional $\$ 50$ (£38) per ton carbon price in 2030 would increase UK natural gas prices by 35 percent, but impacts on retail electricity prices (10 percent), and gasoline prices (6 percent) are relatively modest. In fact, proportionate price increases from carbon pricing tend to be larger in many other G20 countries (see Table). 


\begin{tabular}{|c|c|c|c|c|c|c|c|c|}
\hline \multicolumn{9}{|c|}{ Impact of per ton \$50 Carbon Price on Energy Prices, 2030} \\
\hline \multirow[b]{2}{*}{ Country } & \multicolumn{2}{|c|}{ Coal } & \multicolumn{2}{|c|}{ Natural gas } & \multicolumn{2}{|c|}{ Electricity } & \multicolumn{2}{|c|}{ Gasoline } \\
\hline & $\begin{array}{c}\text { Baseline } \\
\text { Price, \$/GJ }\end{array}$ & $\begin{array}{c}\% \text { Price } \\
\text { Increase }\end{array}$ & $\begin{array}{c}\text { Baseline } \\
\text { Price, \$/GJ }\end{array}$ & $\begin{array}{l}\% \text { Price } \\
\text { Increase }\end{array}$ & $\begin{array}{c}\text { Baseline Price, } \\
\$ / k W h\end{array}$ & $\begin{array}{l}\% \text { Price } \\
\text { Increase }\end{array}$ & $\begin{array}{c}\text { Baseline Price, } \\
\$ / \text { liter }\end{array}$ & $\begin{array}{l}\% \text { Price } \\
\text { Increase }\end{array}$ \\
\hline Argentina & 2.9 & 211 & 2.6 & 100 & 0.08 & 40 & 1.2 & 10 \\
\hline Australia & 2.9 & 148 & 8.5 & 33 & 0.10 & 53 & 1.2 & 11 \\
\hline Brazil & 2.9 & 156 & 2.6 & 99 & 0.12 & 6 & 1.3 & 9 \\
\hline Canada & 2.9 & 173 & 2.6 & 94 & 0.10 & 8 & 0.9 & 13 \\
\hline China & 2.9 & 159 & 8.5 & 32 & 0.09 & 51 & 1.1 & 9 \\
\hline France & 4.9 & 84 & 7.9 & 35 & 0.12 & 2 & 1.7 & 6 \\
\hline Germany & 5.2 & 91 & 7.9 & 34 & 0.13 & 14 & 1.7 & 6 \\
\hline India & 2.9 & 159 & 8.5 & 20 & 0.09 & 65 & 1.2 & 10 \\
\hline Indonesia & 2.9 & 165 & 8.5 & 27 & 0.11 & 53 & 0.5 & 26 \\
\hline Italy & 5.2 & 91 & 7.9 & 35 & 0.13 & 14 & 1.8 & 6 \\
\hline Japan & 2.9 & 158 & 8.5 & 33 & 0.11 & 32 & 1.3 & 8 \\
\hline Korea & 2.9 & 156 & 8.5 & 33 & 0.14 & 36 & 1.4 & 4 \\
\hline Mexico & 2.9 & 156 & 2.6 & 110 & 0.09 & 55 & 0.9 & 13 \\
\hline Russia & 2.9 & 134 & 6.6 & 36 & 0.13 & 20 & 0.8 & 12 \\
\hline Saudi Arabia & 2.9 & 162 & 6.6 & 40 & 0.19 & 28 & 0.5 & 23 \\
\hline South Africa & 2.9 & 145 & 6.6 & 17 & 0.07 & 78 & 1.1 & 13 \\
\hline Turkey & 2.9 & 159 & 6.6 & 41 & 0.09 & 32 & 1.4 & 8 \\
\hline United Kingdom & 5.7 & 101 & 7.9 & 35 & 0.13 & 10 & 1.6 & 6 \\
\hline United States & 2.9 & 170 & 2.6 & 103 & 0.08 & 39 & 0.7 & 15 \\
\hline Simple Average & 3.4 & 146 & 6.4 & 50 & 0.11 & 34 & 1.2 & 11 \\
\hline
\end{tabular}

- Administration. There are administrative complexities and duplication in coordinating across multiple mitigation instruments. Some current instruments operate at the EU level (e.g., EU ETS) and are therefore not under the UK's sole discretion. The CPS rate could be adjusted, but this does not affect emissions from the household, industrial, and transportation sectors.

\section{Despite recent changes, VED in the UK offers only modest $\mathrm{CO}_{2}$ differentiation compared} to some European peers. First-year VED rates were updated significantly in April 2017 to become more differentiated for vehicles with $\mathrm{CO}_{2}$ emissions rates under $100 \mathrm{~g} \mathrm{CO}_{2} / \mathrm{km}$ and rates for high emission rate vehicles were increased significantly. However, the latter affects only a

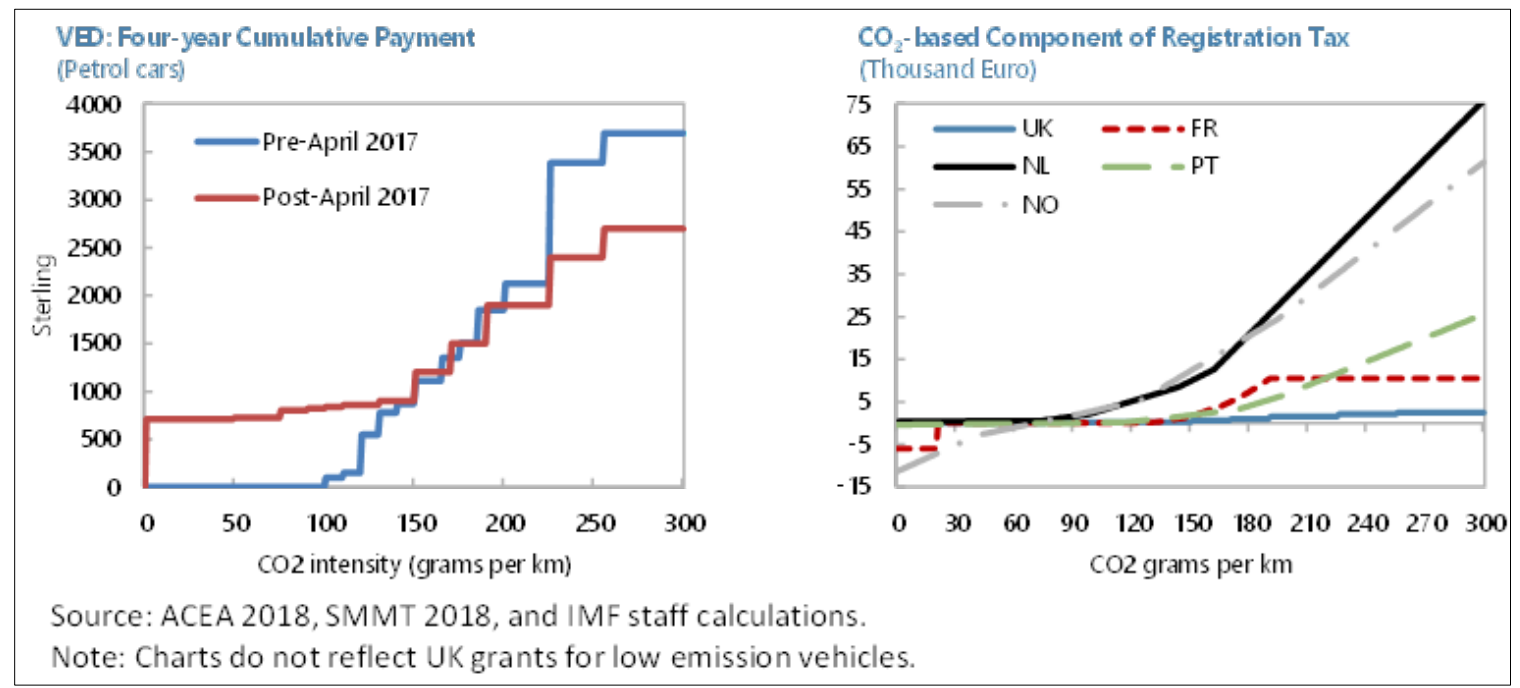


small proportion of the market (less than five percent of new sales emit more than $170 \mathrm{~g}$ $\mathrm{CO}_{2} / \mathrm{km}$ ), and the move to flat payments from the second year onwards (instead of linked to $\mathrm{CO}_{2}$ intensity) made the system less differentiated overall when cumulated over several years (see Figure, left panel). Vehicle tax systems, particularly in Netherlands and Norway, provide much more powerful incentives for low-emission vehicles (right panel).

Over the longer term, phasing out ICE vehicles will erode the base of pre-existing fuel excises, which have traditionally been an important source of revenue. Fuel duty currently raises about 1.4 percent of GDP, or about 70 percent of total fiscal revenue from transportation, about average of that for EU countries (see Figure). Fuel tax revenues could fall by around 0.3 percent of GDP by 2030 with penetration of EVs. ${ }^{33}$ If the Government meets the CCC recommendation of near-zero emissions from transport by 2050 , then fuel duty receipts would tend towards zero.

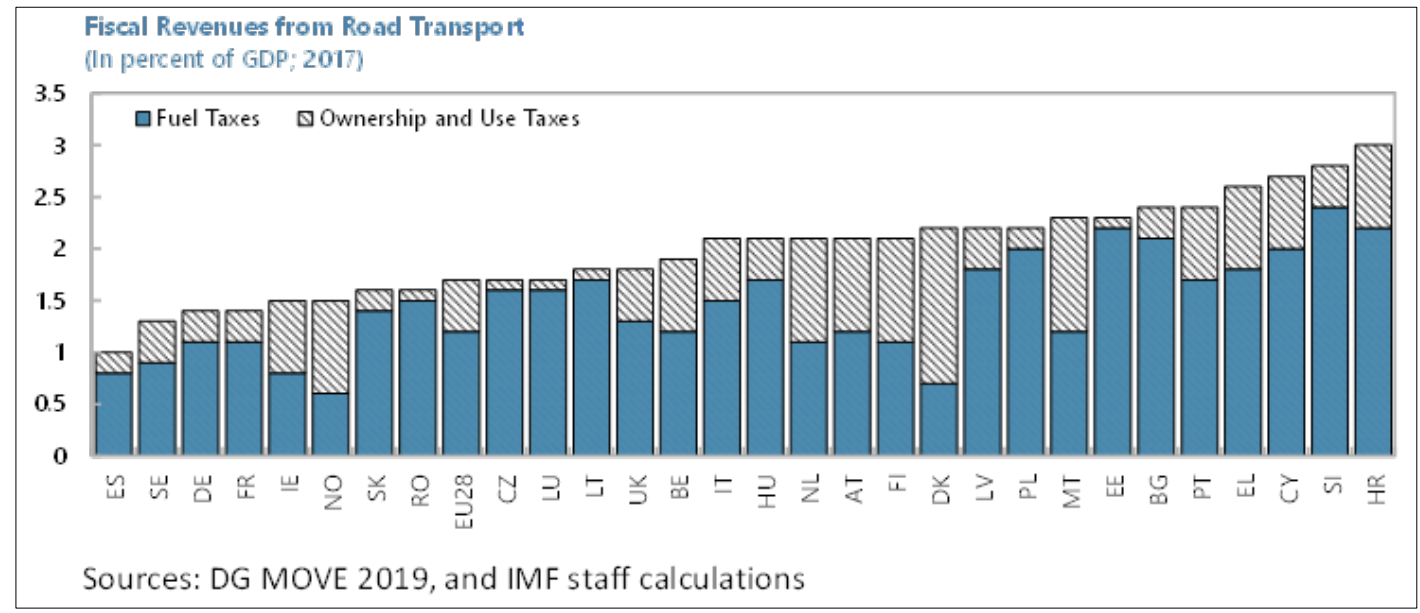

Finally, under the current framework, emissions reductions from domestic policies to reduce power sector and industrial emissions may be offset at the EU level. The UK cannot reduce EU-wide emissions from these sectors if the EU ETS cap is fixed-UK mitigation policies simply lower the EU ETS allowance price in the case. The exception would be if the Market Stability Reserve (MSR), which removes allowances from the system when banked allowances exceed a threshold level, was triggered and the resulting allowances withdrawn under the MRS were permanently retired (rather than put back later into the ETS).

\section{Assessing UK Climate Policy Options Post-Brexit}

The UK authorities have committed to an emissions pricing approach post-Brexit that is at least as ambitious as the existing system (i.e., the EU ETS). The UK has put forward its own domestic ETS proposal to replace the EU ETS, which the UK will leave at the end of 2020 as the Brexit transition period ends. The proposal includes plans to: (i) cover the same emissions

\footnotetext{
${ }^{33}$ Authors' calculation assuming a linear increase in the annual EV sales share to 60 percent by 2030 (based on CCC projections) and 7 percent of the vehicle fleet is replaced each year-these assumptions imply an EV share in the on-road fleet of about 20 percent in 2030.
} 
sources as the current EU ETS; (ii) cut the emissions cap by 5 percent; and (iii) have a fixed auction reserve price, set at $£ 15$ per ton of $\mathrm{CO}_{2}$ (along with price ceilings to be specified). In case of a no-deal Brexit, a carbon tax would replace the EU ETS. The carbon tax would: (i) be set at a level comparable with the EU ETS price; (ii) allow infra-marginal exemptions for emissions sources granted free allowances under the EU ETS; and (iii) maintain the level of total carbon pricing across the UK economy at similar levels. The CPS for electricity generators would remain in place.

As UK policymakers craft a domestic substitute for the EU ETS, they might consider a more comprehensive reform, combining an economywide carbon price with sectoral mitigation instruments, especially feebates. This section discusses such a policy framework, taking economywide and sectoral policies in turn.

\section{A. Economywide}

Carbon pricing has a central role in mitigation policy... As carbon charges are passed forward into higher prices for carbon-based fuels, electricity, and so on (or passed back to suppliers of these fuels) this promotes the full range of behavioral responses for reducing emission rates by sector (e.g., emissions per $\mathrm{kWh}$ of power generation, per ton of steel, or per $\mathrm{km}$ driven) and reducing the overall demand for energy (e.g., through reducing the demand for electricity, steel, vehicle $\mathrm{km}$ travelled).

...but getting basic design details right is critical. Well-designed carbon pricing requires: comprehensively covering emissions (without undue administrative burden); establishing a robust and predictable emissions price (which is important for mobilizing clean technology investment with high upfront cost); exploiting fiscal opportunities (which is especially important given the rapid, crisis-induced run up in debt); and ensuring compatibility with reinforcing sectoral instruments (to ensure these instruments further reduce emissions rather than emissions prices).

A carbon tax is the most natural instrument for meeting these criteria... A carbon tax would integrate carbon charges into existing road fuel excises and apply similar charges to the domestic supply of other oil products, coal, and natural gas. The tax rate can be set to ramp up automatically at a default rate over time. Revenues would be collected directly by the Treasury and could then be allocated across environmental spending (e.g., clean infrastructure investments, assistance to groups vulnerable to the clean energy transition) and general purposes (e.g., lessening the need for broader tax increases for fiscal consolidation). Additional mitigation instruments at the sectoral level would further reduce emissions with no effect on the carbon tax rate.

...but ETSs can largely be designed to mimic a carbon tax making the choice of instrument less important than its design. Although the existing EU ETS applies to downstream emissions (i.e., at the point of fuel combustion) from the power and industry sector, an ETS could be 
extended midstream to suppliers of fuels for buildings and transportation. ${ }^{34}$ Under pure ETS systems annual emissions are fixed while emissions prices vary with market conditions, but price uncertainty can be contained through an exogenous price floor (e.g., a minimum price for auctioned allowances as the UK proposes) that rises over time. With allowances fully auctioned, an (equivalently scaled) ETS would raise the same revenue as a carbon tax and funds could be transferred to the general budget. And - if the floor price is binding - reinforcing mitigation instruments reduce emissions rather (as under a fixed emissions cap) reducing allowance prices. An ETS may have some practical attractions over a carbon tax in the UK, as it builds off capacity for the existing EU ETS (which has been in place for 15 years) and the emissions cap can be aligned with carbon budgets. But carbon tax administration is also straightforward and the ramp up rate for the carbon tax can be periodically adjusted (if needed and in coordination with reinforcing measures) to keep emissions within carbon budgets. ${ }^{35}$

A UK ETS could be linked to the EU ETS. A linked ETS system could be more efficient than a standalone UK system, in the sense that a larger pool of participants results in more costeffective abatement opportunities and greater market liquidity for trading purposes. It would also ensure a smooth transition for the sectors affected and mitigate inter-EEA competitiveness concerns. On the other hand, supplementary policies would be needed to the extent that UK climate objectives remain more ambitious than those set at the EU level. The Swiss experience suggests that linking domestic with EU carbon markets could potentially be a decade-long process. In addition, remaining linked to the EU system would not address the potential offsetting at the EU levels of extra UK emissions reductions from reinforcing measures - unilateral UK actions would translate into lower ETS prices (unless offset by allowance withdrawals through the MSR).

\section{Ideally, the carbon price} (i.e., tax rate or floor price in an ETS) would be aligned with emissions objectives but the needed price is uncertain... IMF staff have developed a spreadsheet tool ${ }^{36}$ to project emissions on a country-bycountry basis and the emissions,

\begin{tabular}{|c|c|c|c|c|}
\hline \multirow{2}{*}{ Country/Region } & \multirow{2}{*}{$\begin{array}{c}\text { Year } \\
\text { Introduced }\end{array}$} & \multirow{2}{*}{$\begin{array}{l}\text { Price 2019, } \\
\$ / T \text { on } \mathrm{CO}_{2}\end{array}$} & \multicolumn{2}{|c|}{ Coverage of GHGs 2018} \\
\hline & & & Million Tons & Percent \\
\hline \multicolumn{5}{|l|}{ Carbon taxes } \\
\hline Chile & 2017 & 5 & 47 & 39 \\
\hline Colombia & 2017 & 5 & 42 & 40 \\
\hline Denmark & 1992 & 26 & 22 & 40 \\
\hline Finland & 1990 & 65 & 25 & 38 \\
\hline France & 2014 & 50 & 176 & 37 \\
\hline Ireland & 2010 & 22 & 31 & 48 \\
\hline Japan & 2012 & 3 & 999 & 68 \\
\hline Mexico & 2014 & $1-3$ & 307 & 47 \\
\hline Norway & 1991 & 59 & 40 & 63 \\
\hline Portugal & 2015 & 14 & 21 & 29 \\
\hline South Africa & 2019 & 10 & 360 & 10 \\
\hline Sweden & 1991 & 127 & 26 & 40 \\
\hline Switzerland & 2008 & 96 & 18 & 35 \\
\hline \multicolumn{5}{|l|}{ Emissions Trading Systems } \\
\hline California & 2012 & 16 & 378 & 85 \\
\hline China & 2020 & na & 3,232 & \\
\hline European Union & 2005 & 25 & 2,132 & 45 \\
\hline Korea & 2015 & 22 & 453 & 68 \\
\hline New Zealand & 2008 & 17 & 40 & 52 \\
\hline Regional GHG Initiative & 2009 & 5 & 94 & 21 \\
\hline \multicolumn{5}{|l|}{ Carbon price floors } \\
\hline Canada & 2016 & 15 & na & 70 \\
\hline United Kingdom & 2013 & 24 & 136 & 24 \\
\hline
\end{tabular}

\footnotetext{
${ }^{34}$ Several ETSs include transport and heating fuels, such as California, Germany (to be introduced in 2021), New Zealand, Quebec, and Chinese pilot schemes including in Shenzen and Beijing, while the South Korean ETS covers heating but not transportation (e.g., Burke and others 2019, WBG 2020).

${ }^{35}$ For further discussion of carbon taxes tax versus ETS see, for example, IMF (2019b), Goulder and Parry (2008).

${ }^{36}$ See IMF (2019a and b), Parry, Mylonas and Vernon (2020).
} 
fiscal, and economic impacts of carbon pricing and other mitigation instruments. The model starts with recent data on use of fossil and other fuels by major energy sector and then projects fuel use forward using (post-COVID) GDP projections and assumptions about: (i) the income elasticity of demand for energy products; (ii) technological progress that improves energy efficiency and the productivity of renewables; and (iii) future international energy prices. The impact of carbon pricing (and other policies) on fuel use depends on their proportionate impact on future energy prices and the price responsiveness of fuel use-price elasticities are between -0.5 to -0.8 based on empirical evidence and results from energy models. There is, however, inherent uncertainty surrounding emissions projections and the responsiveness of emissions to pricing, particularly for large carbon prices, given, for example, that the availability and adoption of future emissions-saving technologies is difficult to accurately project.

...and likely limited by public and business acceptability. Future acceptability will depend, in part, on the progress of emissions pricing in UK trading partners, which again is uncertain. About 60 carbon pricing schemes currently exist at regional, national, and sub-national level though, aside from a few cases (e.g., Scandinavian countries) prices are mostly around $\$ 5$ to $\$ 25$ per ton (see table) and existing and prospective pricing schemes cover only a fifth of global GHGs. ${ }^{37}$ Prices in these schemes should however rise over time (e.g., Ireland is increasing its carbon tax to $\$ 95$ per ton by 2030).

\section{By itself, a carbon price in the order of £60 (US \$75) per ton would not be enough to meet the UK's 57 percent emissions reduction target for $\mathbf{2 0 3 0} .^{38}$}

The carbon price would cut emissions 18 percent below baseline levels in 2030 whereas reductions of 26 percent are needed to meet the UK emissions pledge. Some G20 countries would also require prices above $\$ 75$ per ton to meet their mitigation targets (e.g., France, Italy, Korea) while some others would require prices below $\$ 25$ per ton (e.g., China, India, South Africa). These differences in needed prices reflect both differences in the stringency of pledges (advanced countries tend to have stronger pledges) and in the price responsiveness of

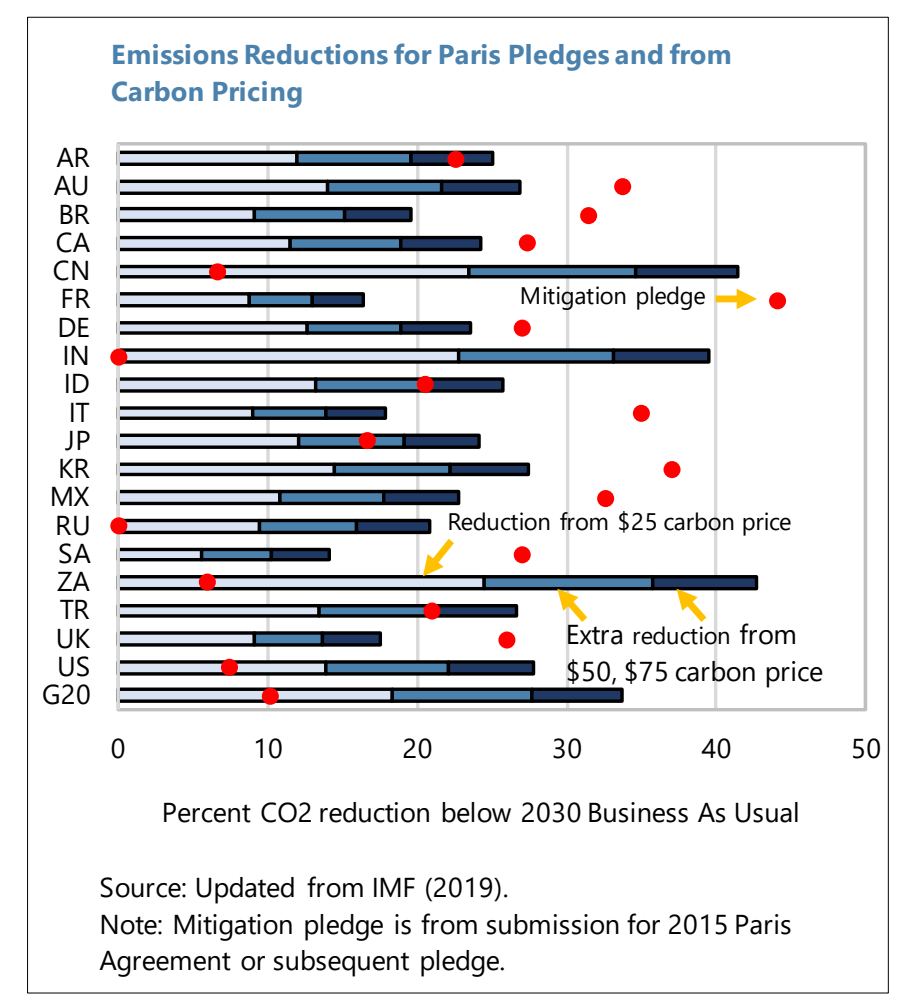

\footnotetext{
37 The carbon price, averaged across global emissions, is only \$2 per ton (calculated from WBG 2020).

${ }^{38}$ Approximately in line with our calculations, Chen and others (2020) estimate using a computable general equilibrium model (Envisage) that the UK would need a uniform carbon price of at least $€ 70$ (£64) per ton to deliver a 50 percent reduction in emissions by 2030, if acting in isolation (i.e., without trade in emissions with the EU) and if the mitigation strategy was solely relying on carbon prices.
} 
emissions (price responsiveness tends to be greater in countries that consume a lot of coal like China, India, and South Africa). To the extent a $£ 60$ carbon price in 2030 , or higher prices beyond 2030, might exceed acceptable levels, reinforcing sectoral policies will need to play a greater role.

A carbon price of $£ 60$ per ton in 2030 could provide a valuable revenue stream for the medium term. It would raise additional annual revenues (relative to a zero-carbon price and accounting for the erosion of pre-existing fuel tax bases) of around 0.8 percent of GDP in 2030.

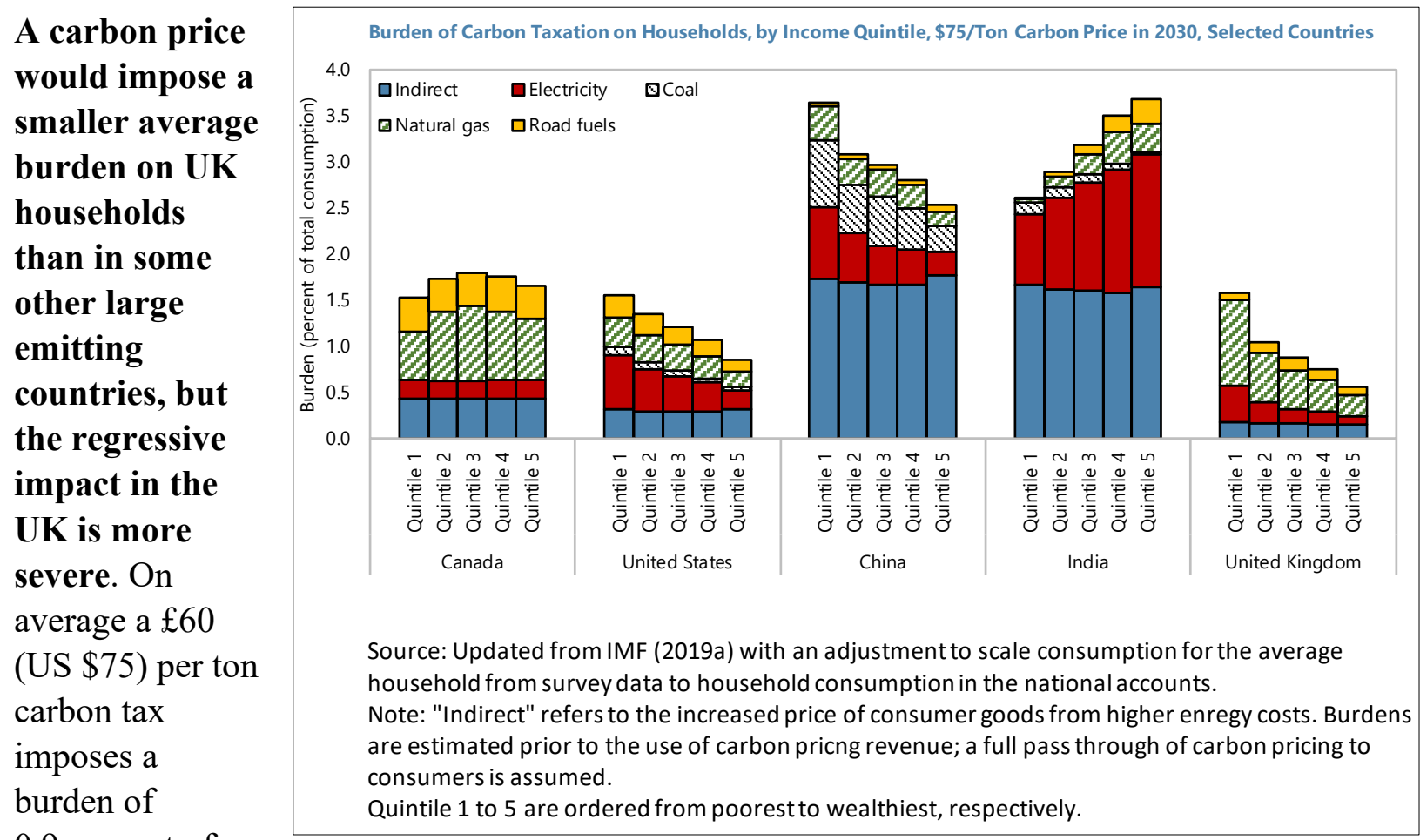

0.9 percent of

consumption for the average UK household in 2030 (relative to no tax)-somewhat less than the burden in other countries like US, Canada, and (especially) China and India (see Figure). The impact is however relatively more regressive in the UK than in other countries, with the burden borne by the bottom income quintile 2.7 times as large (relative to consumption) as for the top income quintile. This reflects the disproportionately high consumption of natural gas (and to a lesser extent electricity) among low-income UK households.

Revenue recycling via targeted compensation packages can protect those most vulnerable, while making fiscal space to finance other climate change reforms, cutting distortionary taxes or funding growth-enhancing investments. Priorities for revenue recycling would be guided by efficiency, equity and acceptability objectives given a country's economic and political circumstances. ${ }^{39}$ Although much of the burden of carbon taxation (in the near to medium term) on the average household is effectively offset when carbon tax revenues are put

${ }^{39}$ Klenert and others (2018). 
back into the economy, this revenue-recycling should disproportionately benefit low-income households (to offset the regressive effect of the carbon tax) while boosting growth (e.g., through improving incentives for work effort and investment). See Annex I for a detailed discussion of the distributional implications of addressing the carbon pricing gap in domestic energy consumption. To maximize economic efficiency, revenue should be used to decrease (or to avoid the need to raise) distortionary taxes such as the labor income tax, or to address critical public investment gaps. ${ }^{40}$

\section{B. Transportation}

A carbon price provides a modest incentive for shifting to zero emission vehicles (ZEVs). ${ }^{41}$ For example, a $£ 60$ per ton carbon price increases the price of a new vehicle with average fleetwide emission rate by about $£ 1,000$ relative to a ZEV (based on assumptions below), or about 3.5 percent of the vehicle purchase price. ${ }^{42}$ A rapid transition to ZEVs will likely require stronger pricing incentives (besides expanding infrastructure for EV charging). ${ }^{43}$

A feebate is a promising policy to reinforce incentives for ZEVs. A feebate would apply a sliding scale of fees to vehicles with above average emission rates and a sliding scale of rebates to vehicles with below average emission rates. They do not charge for average emissions which may increase their acceptability compared with higher fuel taxes, though they are less efficient in the sense they do not encourage people to drive less. Under a feebate, new vehicle sales would be subject to a fee equal to the product of: (i) a $\mathrm{CO}_{2}$ price; (ii) the difference between the vehicle's $\mathrm{CO}_{2}$ per $\mathrm{km}$ and the average $\mathrm{CO}_{2}$ per $\mathrm{km}$ of the (nationwide) new vehicle fleet; and (iii) (discounted) lifetime $\mathrm{km}$ of the average vehicle.

Feebates have several key attractions. They:

- Promote a wide range of behavioral responses - including shifting from high- to lowemission rate ICEs, from ICEs to biofuel and hydrogen vehicles, and from ICEs to EVs (in contrast, tax incentives for EVs would promote only the last response);

- Are cost-effective - they provide the same incremental reward for reducing emissions across

\footnotetext{
${ }^{40}$ Chen and others (2020).

${ }^{41}$ While this section focuses on pricing policies for vehicles, incentivizing cleaner transportation modes should also play a role in reducing the transport emissions (see Arregui and others 2020). Policies to promote cleaner transport modes include pricing measures (e.g., adequate pricing of road vehicle externalities), as well as investment in safe and connected infrastructure, and policies targeted at changing consumer behavior. A shift to cleaner modes, such as walking, cycling, and mass transportation, would have co-benefits in terms of health and reduced congestion.

42 The average new car price in 2019 was $£ 29,000$ (from www.motortrader.com/motor-trader-news/automotivenews/average-car-price-rises-28973-08-08-2012). Although EVs have lower running costs than ICE vehicles, motorists may still be reluctant to purchase EVs given their high upfront cost, limited availability of models, and currently insufficient charging infrastructure.

${ }^{43}$ Meeting both the UK's target for the transport sector and for nationwide emissions will require deviating from the principle of uniform carbon pricing across sectors on cost effectiveness grounds.
} 
vehicle choices (in contrast, emissions standards are not cost effective in the absence of extensive credit trading provisions);

- Do not lose government revenue - if the 'pivot point' (the CO2 emission rate per $\mathrm{km}$ above/below which fees/rebates are applied) equals the new fleetwide average emission rate observed in the preceding year (in contrast, EV subsidies impose a fiscal cost);

- Do not impose a new tax burden on households - revenue-neutrality implies no effect on the price of a vehicle with the average emission rate, so the average household is no worse off (in contrast, higher fuel taxes impose a first order tax burden on motorists which make them more challenging politically), ${ }^{44}$ and

- $\quad$ Are easily integrated into existing formulas such as VED schedules - no new capacity is needed to implement a vehicle feebate in the UK.

\section{Feebates could provide strong additional incentives to complement carbon pricing.} For example, feebates with a carbon price of $£ 300$ per ton would provide an EV subsidy of $£ 4,694$ at current fleetwide average emission rates. At the same time, taxation for high

\begin{tabular}{|c|c|c|c|c|c|c|c|c|}
\hline \multicolumn{9}{|c|}{ Impact of Feebate on New Vehicle Purchase Prices, 2017} \\
\hline \multirow{4}{*}{$\begin{array}{c}\text { Vehicle } \\
\text { classification }\end{array}$} & \multirow[t]{3}{*}{ Registrations } & \multirow{3}{*}{$\begin{array}{l}\text { Average new } \\
\text { car emissions }\end{array}$} & \multicolumn{2}{|c|}{$\begin{array}{l}\text { Current vehicle } \\
\text { excise duty (VED) }\end{array}$} & \multicolumn{2}{|c|}{$\begin{array}{l}\text { Feebate: pivot point } \\
119 \mathrm{~g} \mathrm{CO} 2 / \mathrm{km}^{\mathrm{a}}\end{array}$} & \multicolumn{2}{|c|}{$\begin{array}{l}\text { Feebate: pivot point } \\
65 \mathrm{~g} \mathrm{CO} 2 / \mathrm{km}^{\mathrm{a}}\end{array}$} \\
\hline & & & band & $\operatorname{tax}$ & \multicolumn{4}{|c|}{$£ /$ ton $\mathrm{CO} 2$} \\
\hline & & & & & 100 & 300 & 100 & 300 \\
\hline & '000s & $\mathrm{g} \mathrm{CO}_{2} / \mathrm{km}$ & & $£$ & \multicolumn{4}{|c|}{ change in purchase price, $£$} \\
\hline Mini & 69 & 105.9 & $\mathrm{~F}$ & 280 & -171 & -513 & 538 & 1,615 \\
\hline Supermini & 748 & 110.7 & G & 300 & -108 & -324 & 601 & 1,804 \\
\hline Lower medium & 728 & 115.8 & G & 300 & -41 & -123 & 669 & 2,006 \\
\hline Upper medium & 243 & 120.5 & G & 300 & 21 & 63 & 730 & 2,191 \\
\hline Executive & 123 & 121.6 & G & 300 & 35 & 106 & 745 & 2,235 \\
\hline Luxury & 9 & 178.9 & J & 940 & 790 & 2,369 & 1,499 & 4,497 \\
\hline Sports & 48 & 155.0 & 1 & 640 & 475 & 1,425 & 1,184 & 3,553 \\
\hline Dual purpose & 460 & 141.3 & $\mathrm{H}$ & 340 & 295 & 884 & 1,004 & 3,012 \\
\hline MPV & 112 & 132.0 & $\mathrm{H}$ & 340 & 172 & 517 & 882 & 2,645 \\
\hline Electric & 46 & 0 & A & 0 & $-1,565$ & $-4,694$ & -855 & $-2,566$ \\
\hline Total/average & 2,586 & 119 & & 312 & 0 & 0 & 0 & 0 \\
\hline \multicolumn{9}{|c|}{ Sources. SMMT (2018). } \\
\hline \multicolumn{9}{|c|}{$\begin{array}{l}\text { Notes. }{ }^{a} \text { Assumes discounted lifetime mileage of } 131,600 \mathrm{~km} \text { based on } 16 \text { year life, vehicles are driven on average } 1,145 \mathrm{~km} \text { a } \\
\text { year, annual reduction in driving of } 3 \% \text {, and } 5 \% \text { discount rate. Pivot points of } 119 \text { and } 65 \mathrm{~g} \mathrm{CO}_{2} / \mathrm{km} \text { are based on new UK fleet } \\
\text { average for } 2017 \text { and EU target for } 2030 \text { respectively. }\end{array}$} \\
\hline
\end{tabular}
subsidies would decline (in proportion) with declines in the fleetwide average emission rate (see table), but this is appropriate as EV prices continue toward cost-parity with ICE vehicles.

\section{Broader pricing reforms could address other transportation externalities and maintain revenue despite progressive erosion of fuel tax bases. These reforms include (see Box 1):} (i) charges (for ICE vehicles and ZEVs alike) related to $\mathrm{km}$ driven that vary with the prevailing degree of road congestion; and (ii) promoting a market-driven transition to pay-as-you-drive auto insurance.

\footnotetext{
${ }^{44}$ Feebates are likely to be progressive, benefitting lower income households on net to the extent they are more likely to purchase small (fuel efficient) vehicles.
} 


\section{Box 1. Broader Reforms to the Pricing of Road Transport}

Traffic congestion imposes large external costs on road users. Congestion is excessive because motorists do not account for their impact on slowing road speeds for other road users. The external cost (the cost one vehicle imposes on other road users) was less than 3.5 pence per vehicle $\mathrm{km}$ for about 75 percent of driving in the UK in 2015, but external costs increase sharply as the traffic volume to road capacity ratio approaches unity (see Table) - external costs were 92 and 196 pence per km when this ratio is $0.75-1$ and over 1 respectively. Averaged across road classes estimated external costs were 14.3 pence per $\mathrm{km}$.

Congestion can be efficiently managed (for given road capacity) through $\mathbf{k m}$-based taxes varying by location and time of day. Per km tolls on busy roads that progressively rise and fall over the rush hour exploit all behavioral responses for reducing congestion (e.g., setting off before or after the peak of the rush hour; shifting to off-peak travel, less congested roads, or public transport; carpooling; reducing trip frequency). Developments in metering technologies such as global positioning systems imply that people's driving could be tracked and billed accordingly. ${ }^{1} \mathrm{~km}$-based charging might be promoted through subsidizing/taxing vehicles with/without monitoring capacity during a transition period with monitoring capacity eventually becoming mandatory. Unlike fuel taxes, km-based taxes provide a robust general revenue base which would be unaffected by decarbonization of transportation and is especially valuable given fiscal pressures from the COVID-19 crisis.

Transitioning from lump-sum to pay-as-you-drive (PAYD) automobile insurance, under which premiums vary in proportion to the policyholder's annual $\mathrm{km}$, would further reduce driving and help to internalize traffic accident externalities. Motorists do not account for various accident risks to others posed by their own driving (e.g., injury risks to pedestrians and to other vehicle occupants in multi-vehicle collisions, third-party property and medical costs) (see Parry 2004). Existing rating factors, as determined by insurance companies, could be used to set per km charges for different drivers as an (albeit imperfect) proxy for external accident risk: drivers with prior crash records, for example, would pay higher variable charges and would have the greatest incentives to drive less. The transition to PAYD could occur on a voluntary basis, with the government kickstarting the process using tax incentives. ${ }^{2}$ Drivers with belowaverage annual $\mathrm{km}$ would have the strongest incentives to take up PAYD and as they switched, premiums would rise for the remaining pool of drivers with lump-sum insurance, encouraging further shifting to PAYD. On average, PAYD would raise the marginal cost of driving by around 4 pence per $\mathrm{km}$ (while reducing the average accident risk for all drivers). ${ }^{3}$

${ }^{1}$ The administrative costs would however be higher than for collecting fuel taxes, due to the need to charge individuals rather than fuel distributors. An alternative, bottom-up approach would be to progressively expand congestion-charging zones (e.g., in London), though this would be far less comprehensive than a nationwide charging system.

${ }^{2}$ Government incentives may be needed to overcome obstacles to the private development of PAYD. When an insurer charges by the $\mathrm{km}$, its costs are reduced to the extent that its own customers reduce their accident risk by driving less. However, the costs to other insurance companies also are lowered because the risk of multi-car accidents for their own customers is lower, but savings cannot be captured by the company offering the km-based insurance.

${ }^{3}$ Assuming an annual insurance payment of $£ 500$ and $11,450 \mathrm{~km}$ driven per year. 


\section{Industry}

\section{Carbon pricing for industry is constrained in practice, not least by concerns about} competitive impacts. The burden of carbon pricing on industry consists of the costs of cutting emissions (e.g., from switching to cleaner but more expensive technologies) and the, typically much larger, tax or allowance purchase payments for remaining emissions (Box 2). Under the EU ETS, energy-intensive, trade-exposed (EITE) industries have received free allowance allocations to offset the burden of pricing (given the limited ability of these firms to pass the burden forward in higher consumer prices) though this compensation mechanism becomes less effective at deeper levels of abatement. If the UK were to implement a border carbon adjustment (BCA) on embodied carbon for EITE industries this might enable higher carbon pricing for domestic industries, though even a carefully designed BCA (e.g., that limited administrative burdens and the risk of retaliation by trading partners) might take at least several years to implement.

\section{Feebate schemes for industries could reinforce incentives for reducing emissions intensity} but with a much smaller burden on the industries than from higher carbon pricing (Box 2). Under a feebate firms would pay a fee equal to the product of: (i) a $\mathrm{CO}_{2}$ price; (ii) the difference between the firm's $\mathrm{CO}_{2}$ per unit of production and the industry average $\mathrm{CO}_{2}$ per unit of production; ${ }^{45}$ and (iii) their production level. The lower burden under a feebate may enhance their acceptability and reduce the pressure for a BCA. Box 3 provides illustrative comparisons of the impacts of carbon pricing and feebates on production costs in the steel and cement industries.

\section{Box 2. The Burden on Industry from Carbon Pricing and Feebates}

The burden-or increase in private production costs - for an industry from carbon mitigation policies is depicted in the figure. Here the upper, middle, and lower upward sloping curves are respectively the marginal cost of reducing emissions through reducing domestic output, reducing the emissions intensity of output (see Box 3) and the envelope of these two curves. A carbon pricing policy reduces emissions by $\Delta \mathrm{E}^{\text {tot }}$, with $\Delta \mathrm{E}^{\text {int }}$ and $\Delta \mathrm{E}^{\text {out }}$ coming from reduced emissions intensity and reduced output respectively. The burden of the carbon price includes the (second order) efficiency cost of the behavioral responses (the red triangle) reflecting the cost of adopting cleaner (but costlier) production methods. The burden also includes the (first order) transfer payment (i.e., the tax payment to the government or allowance purchases) reflecting the charge on remaining emissions (the blue rectangle).

\footnotetext{
45 The focus should be on direct emissions from fuel combustion rather than indirect emissions from use of electricity as the latter are covered by carbon pricing and perhaps sectoral measures for the power sector.
} 
Box 2. The Burden on Industry from Carbon Pricing and Feebates (concluded)

A feebate is less efficient than carbon pricing and does not raise revenue but can impose a much smaller burden on industries. A feebate promotes reductions in emissions intensity but does not charge for remaining emissions and therefore (to an approximation) has no impact on output. The burden under a feebate (assuming the total emissions reduction is the same as under the carbon price) includes a higher efficiency cost (the extra green triangle in the Figure) but there is no corresponding transfer payment.

\section{Box 3. Illustrative Impacts of Carbon Pricing and Feebates on Production Costs for Steel and Cement}

Steel. About 40 percent of steel is produced using an integrated process involving heating coal to form coke, feeding coke and iron ore into a blast furnace, and using an oxygen furnace to purify the molten metal - the process produces about two tons of $\mathrm{CO}_{2}$ per ton of steel. ${ }^{1}$ Alternatives include an electrified process using scrap metal, currently about 60 percent of production, and emerging technologies - for example, applying carbon capture and storage (CCS), or feeding an electric furnace with iron made by direct reduction (e.g., using natural gas). These alternatives produce $\mathrm{CO}_{2}$ emissions of about 0.3-0.4 tons per ton of steel.

A carbon price of $£ 40 /$ ton of $\mathrm{CO}_{2}$ would increase the cost of integrated production by about $£ 80 /$ ton of steel through the first-order transfer payment, about 20 percent of recent steel prices. ${ }^{2}$ And it would increase the cost under alternative technologies by about $£ 15 /$ ton of steel. ${ }^{3}$ In contrast, under a feebate the cost increase for integrated production (given the current industry average emission rate of 1 ton of $\mathrm{CO}_{2}$ per ton of steel) would increase $£ 40$ per ton of output, while alternative technologies would receive a subsidy of about $£ 25$ per ton of output.

Cement. About 90 percent of cement is produced using traditional kilns to decompose calcium carbonate into clinker and $\mathrm{CO}_{2}$ and then using mills to mix clinker with other minerals like limestone and grinding it - the process produces about 1 ton of $\mathrm{CO}_{2}$ per one ton of cement, with process emissions contributing about 70 percent of these emissions. Alternatives include state-of-the-art plants in terms of energy efficiency, currently about 10 percent of production, and CCS - either post-combustion (where $\mathrm{CO}_{2}$ is extracted from exhaust gases) or oxy-combustion (where fuel is burned with a mixture of pure oxygen and exhaust gases). State-of-the-art plants largely eliminate non-process emissions. Post- and oxy-combustion reduce emissions about 55 and 85 percent respectively, while increasing capital costs by about 25 and 100 percent respectively.

A carbon price of $£ 40 /$ ton of $\mathrm{CO}_{2}$ would increase the cost of traditional production about $£ 40$ per ton of cement, or about 70 percent, ${ }^{4}$ while increasing the price of more efficient and CCS-fitted plants by $£ 28$, and £6-20 per ton of output respectively through the first-order transfer payment. In contrast, a feebate with price $£ 40 /$ ton of $\mathrm{CO}_{2}$ would only increase the cost of traditional production by $£ 4$ per ton of cement, while providing a subsidy to more efficient and CCS-fitted plants of $£ 8$ and $£ 16-30$ per ton of output.

${ }^{1}$ Unless otherwise noted, all data in this box is taken from van Reijven and others (2016), based on western European averages.

${ }^{2}$ The integrated approach produces about 2 tons of $\mathrm{CO}_{2}$ per ton of steel. Steel prices are from www.focuseconomics.com/commodities/base-metals/steel-europe.

${ }^{3}$ Technology switching is more likely to take the reform of retrofitting existing plants, rather than scrapping plants and building new ones, given that existing steel factories can potentially produce for several decades. Incentives will vary across plants, for example with local fuel and electricity prices.

${ }^{4}$ Cement prices are currently around $£ 55$ per ton (from EC 2018, pp. 11). 


\section{Buildings}

\section{Promoting improvements in residential energy efficiency is a "low regret" policy with positive distributional implications.}

- The relatively aged UK building stock remains one of the most inefficient in Europe, with only about one third of houses meeting Energy Performance Certificate (EPC) band C or better. $^{46}$

- Many available abatement measures (e.g., insulation) appear to be self-financing. The annual running cost of an EPC C rated home is about $£ 270$ lower than average EPC D, and $£ 650$ lower than average EPC E. For a typical home, absence of loft and cavity wall insulation add about $£ 220$ a year to bills. Private payback is expected to be under four years. ${ }^{47}$

- The associated abatement potential is large. Total energy use could be reduced by about a quarter by 2035 through cost effective investments in energy efficiency and low carbon heat. $^{48}$

- With just ten percent of fuel, poor households living in properties rated EPC C or better, improving residential efficiency is likely to have positive distributional implications, helping to mitigate the impact of future increases in carbon prices.

Carbon pricing needs to be reinforced by supplementary measures to overcome additional market failures in the building sector. Renovation rates are typically held back by liquidity constraints, cost-benefit mismatches between owners and renters, and unawareness or uncertainty of potential energy savings from renovation. ${ }^{49}$

The UK government's stated ambitions for improving building efficiency will need to be accompanied with more concrete delivery plans. All new homes will be required to be highly energy efficient and built with low-carbon heat by 2030, but the trajectory for tightening standards remains to be set out. Actions via new homes takes far too long because of low replacement rate, so the government has also stated its intention to retrofit existing housing stock to at least EPC band C by 2035. Nonetheless, current policies are failing to drive an uptake, including for cost-effective measures such as loft-insulation.

\footnotetext{
${ }^{46}$ EPCs are a rating scheme to summarize the energy efficiency of buildings in the European Union, ranging between A (Very efficient) to $\mathrm{G}$ (Inefficient).

${ }^{47}$ Figures from CCC (2018).

${ }^{48}$ Rosenow and others (2018).

${ }^{49}$ See Arregui and others (forthcoming), Burke and others (2019), and ZCC (2020).
} 


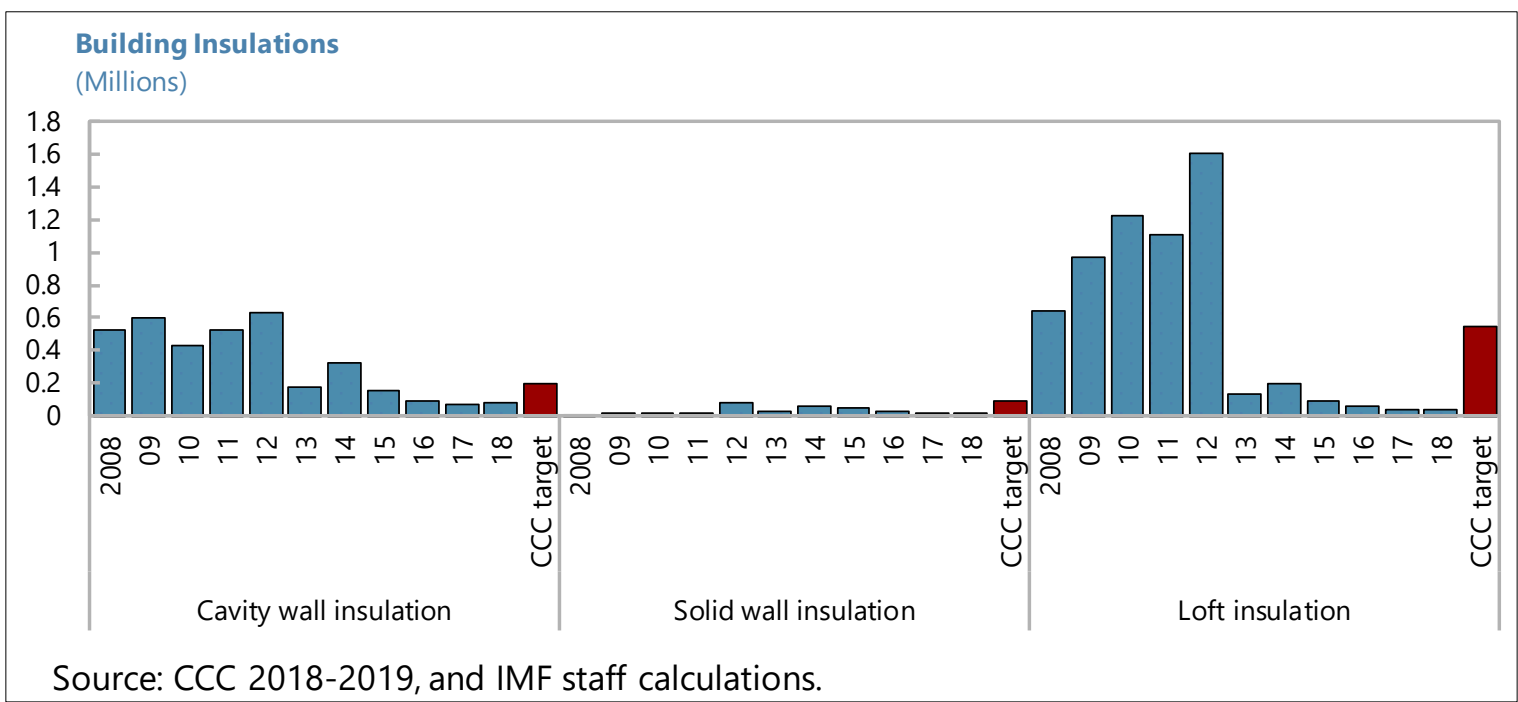

A package of regulatory and fiscal measures for the residential sector could reinforce carbon pricing. Potential instruments include:

- On the regulatory front, there should be clear trajectories of standards across the housing stock for both energy efficiency and low-carbon technologies - the latter could culminate in a ban on the installation of new gas boilers by mid-2030s at the latest (given boiler lifetimes of around 15 years).

- A tax-subsidy (feebate) scheme involving revenues from an interim tax on gas heating technologies (with rate increasing through mid-2030s) funding subsidies for electric heat pumps or hydrogen boilers.

- Attractive finance mechanisms might also overcome the typically large up-front costs of improving household energy efficiency (e.g., insulation measures). ${ }^{50}$

- Differentiating rates of stamp duty and/or council tax to further incentivize the take-up of energy efficiency measures. ${ }^{51}$

\section{E. Other Sectors}

Feebates could be applied to power generation and to electricity-consuming products. A feebate applied to power generation would impose a fee on generators equal to the product of: (i) a $\mathrm{CO}_{2}$ price; (ii) the difference between their $\mathrm{CO}_{2} /$ kilowatt hour $(\mathrm{kWh})$ averaged across their

\footnotetext{
${ }^{50}$ The scale and scope of policy initiatives will need to be more extensive than that of current schemes. For example, the Energy Company Obligation (ECO) which seeks to remove the barrier of initial costs of energy efficiency improvements, is focused on the most vulnerable households and "hard to treat" homes. The Renewable Heat Incentive (RHI), which provides financial support over time to promote the market rollout of renewable heat technologies such as heat pumps, and the proposed switch to upfront grants once the RHI expires in 2021, would have to be scaled up significantly (CCC 2020).
}

${ }^{51}$ CCC (2020). 
plants and the industry-wide average $\mathrm{CO}_{2} / \mathrm{kWh}$; and (iii) their electricity output. ${ }^{52}$ Feebates applied to energy-consuming products like refrigerators, heating systems, and other energyconsuming capital would impose a fee equal to the product of: (i) a per unit energy charge; and (ii) the difference between their energy consumption rate and the industry-wide energy consumption rate for that product. ${ }^{53}$ Again, these feebates have a much smaller impact on electricity or product prices than comparable carbon pricing as they avoid the pass through of carbon tax revenues or allowance rents in higher prices. The case for these reinforcing instruments is less pressing than for other sectors however, given the already substantial reductions in emissions intensity of the power sector.

For the most part, other emissions sources from forestry, fugitive emissions, fluorinated gases, and landfills can be addressed through various emissions taxes, feebates, and regulations. Carbon storage through land use, land-use change, and forestry (LULUCF) could be promoted through a national feebate system taxing landowners who store less carbon on their property relative to storage in a baseline year and giving rebates to landowners who increase carbon storage. ${ }^{54}$ Methane leakage during extraction, processing, and transport of petroleum and gas could be taxed in proportion to a default leakage rate, with rebates for firms that demonstrate a leakage rate below the default rate. Fluorinated ( $\mathrm{F}-$ ) gases used in refrigerants, foams, aerosols, and fire extinguishers could be taxed (if the UK withdraws from the current regulatory framework for these emissions). ${ }^{55}$ Waste emissions have already fallen considerably - the existing landfill tax should however be at least adjusted for inflation and extended to emissions from incineration. ${ }^{56}$

Agriculture is the more challenging sector given the difficulty of directly monitoring farmlevel emissions, though fiscal policies can still play an important role. Agricultural GHG emissions account for about ten percent of total emissions, and include methane emissions from cow and pig operations and nitrous oxide emissions from soil and fertilizer practices. Taxes could be imposed per head of livestock, using default emission rates, and on fertilizer inputs, Alternatively, farmers could be charged for the difference between their $\mathrm{CO}_{2}$ equivalent emissions per hectare and the industry average per hectare (using farm-level data on acreage,

\footnotetext{
${ }^{52}$ Feebates would promote switching from coal to gas and shifting to renewables, natural gas combined cycle generation with carbon capture and storage (NGCC), biomass, as well as improvements in the efficiency of generation (subsidies for renewables would exploit only the last response). NGCC generators with fast ramp up speeds can complement intermittent renewable generators (e.g., Verdolini and others 2018). See Krupnick and Parry (2011) for further discussion of power sector feebates.

${ }^{53}$ For refrigerators, for example, the energy consumption rate is $\mathrm{kWh} / \mathrm{cubic}$ foot cooled. Promoting electricity conservation is still important, even if power generation were decarbonized, to ensure demand/supply balance given constraints on renewable generation sites.

${ }^{54}$ Carbon storage can be assessed from a combination of satellite imagery, aerial photography, and on-the-ground tree sampling. See Parry (2020) for more discussion on the rationale for, and design of, feebates for the forestry sector.

${ }^{55}$ See HOC (2018). Some countries (e.g., Denmark, Norway, Poland, Spain) have introduced taxes on these gases with rates of about $\$ 5-\$ 40$ a ton of $\mathrm{CO} 2$ equivalent.

${ }^{56}$ See ZCC (2020) for more discussion.
} 
livestock herds, and crop production and default emission rates), which may have greater acceptability than a tax on estimated emissions. At the consumer level, fiscal incentives might promote a shift from meat- to plant-based diets.

\section{International Pricing Schemes}

As President of COP26, the UK might promote dialogue on complementing the Paris process with additional mechanisms to scale up global mitigation, notably a carbon price floor arrangement among large emitters. ${ }^{57}$ An international carbon price floor arrangement would be the most efficient approach for addressing countries' concerns about the competitiveness impacts of carbon mitigation. The arrangement need only include a small number of large emitting countries - if a uniform carbon price were imposed across G20 countries (who collectively account for 80 percent of global $\mathrm{CO}_{2}$ emissions), then more than 80 percent of the emissions reductions would be in three countries alone - China, India, and the US. A carbon price floor can be designed equitably with lower requirements for non-advanced countries to reflect their lower per capita income and small contribution to the historical stock of atmospheric GHGs. The floor could also be designed flexibly to accommodate different policy approaches at the national level including carbon taxes, ETSs, and (in exceptional cases) combinations of feebates and regulations if they achieve the equivalent emissions outcome as implementing the price floor. ${ }^{58} 59$

\section{A carbon piece floor could be highly effective in} scaling up global mitigation. For illustration, if advanced G20 countries were subject to a price
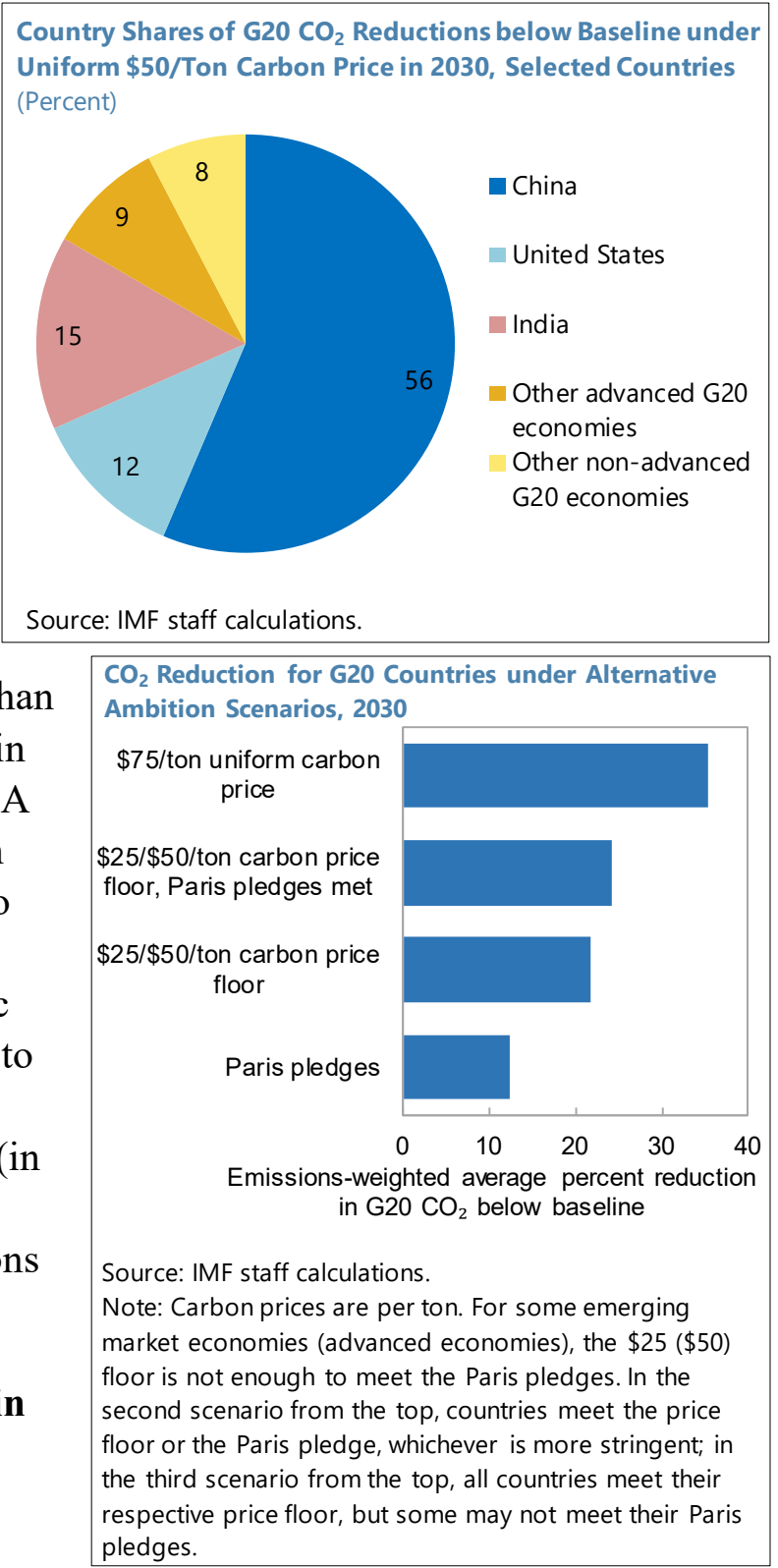

\footnotetext{
${ }^{57}$ See Schwerhoff (2016) for a broader discussion of the positive effects from leadership on climate policy.

${ }^{58}$ The latter flexibility provision should be used sparingly as it would require external verification and would add complication to the price floor arrangement.

${ }^{59}$ In the absence of an international carbon price floor, implementing a carbon border adjustment mechanism would help prevent carbon leakage (subject to the resolution of various political and design considerations), so that cutting production emissions in a country does not lead to higher emissions abroad. See Chen and others (2020) for a discussion in the European context.
} 
floor of $\$ 50$ per ton in 2030 and non-advanced G20 countries a price floor of only $\$ 25$ per ton, this would still double emissions reductions in G20 countries over and above the reductions implied by meeting their current mitigation pledges (see Figure).

Implementation issues would need to be fleshed out but seem manageable. For example, the focus could initially be on emissions from the power and industry sectors as: (i) these emissions are generally the most responsive to pricing and therefore play the key role in the early stages of clean energy transitions; (ii) most ETSs currently in place are limited to these sectors; and (iii) historically, fuels in these sectors were largely untaxed (or subject to minimal taxes in terms of $\mathrm{CO}_{2}$ equivalent taxes) making for a clean comparison to a baseline without carbon pricing. Over time, as the arrangement transitions to broader coverage of fossil fuel emissions, and measuring conventions are developed, the focus might transition to countries' 'effective' carbon prices which take account of the possibility of incomplete coverage of formal carbon pricing schemes and changes in pre-existing energy taxes (which are typically large for transport fuels) — participants could agree to increase their effective carbon prices by a given absolute amount over time.

\section{Participation by non-advanced countries might be promoted through various carrots and} sticks. Besides being subject to a stricter price floor requirement, advanced countries might also provide transparent financial support for non-advanced countries and transfer of clean energy technologies. Participants could also be excluded from the prospective EU BCA.

\section{The UK could also promote dialogue at COP26 on carbon pricing schemes for} international maritime emissions... The International Maritime Organization (IMO) has pledged to reduce within-sector $\mathrm{CO}_{2}$ emissions by 50 percent below 2008 levels by 2050 . Achieving this target will require progressive penetration of zero emission ships (e.g., using hydrogen fuels). A carbon levy would raise funds for the R\&D and infrastructure required for bringing these ships to market and it provides the critical price signal for closing the gap between their cost and that of traditional ships to promote deployment. However, a pure carbon price with the required price signal would raise considerably more revenue than needed for research and investment, and debate over how to allocate this revenue might delay implementation of the pricing scheme. An alternative is to use a feebate variant where ship operators are taxed on the difference between their emissions per ton-km and a pivot point emission rate, scaled by their tonnage - the feebate price can be set aggressively to promote deployment, with the pivot point then chosen to meet a revenue target. ${ }^{60}$

...and international aviation emissions. The International Civil Aviation Organization (ICAO) has pledged to stabilize industry emissions at current levels from 2026 onwards, through a scheme where operators can purchase international emissions offsets to cover any excess of their emissions above the benchmark. More ambitious emissions targets will ultimately be required however, for deep decarbonization of the sector, as well as a more robust price signal (than can

\footnotetext{
${ }^{60}$ See Parry, Heine and others (2020).
} 
be provided by offset markets ${ }^{61}$ ) to promote development and deployment of the clean fuel alternatives. As with maritime, a variation of pricing that decouples the (strong) price signal from the amount of revenues raised may be needed.

\section{Summing UP}

Immediate priorities for the UK government include establishing a domestic carbon pricing scheme to replace the EU ETS and achieving concrete progress to move global mitigation forward at COP26. Whatever domestic pricing instrument is adopted, it should be comprehensive, ideally remove some of the sectoral differences in carbon prices due to the plurality of existing pricing schemes, establish a robust price trajectory aligned, insofar as politically acceptable, with future carbon budgets, and with fiscal opportunities fully exploited. The UK will also need to better align future carbon budgets with the emissions neutrality target for 2050 and phase in sectoral measures providing strong additional incentives to deploy clean technologies, particularly in transport, industry and buildings - this paper emphasizes the potential attraction of feebates in this regard. At the international level, pledged mitigation effort falls well short of what is needed for climate stabilization goals, and countries acting unilaterally may lack incentives for greater ambition. The UK government has a unique opportunity to kickstart dialogue among large emitting countries on a second, but complementary, track to the Paris process to explore institutional mechanisms for scaling up global action - this paper emphasizes the potential role of international carbon price floors and innovative pricing schemes for international transportation in this regard.

\footnotetext{
${ }^{61}$ The current offset price is below $\$ 1$ per ton of $\mathrm{CO}_{2}$ and large offset prices that pass an additionality requirement seem unlikely (e.g., Fearnehough and others 2018).
} 


\section{REFERENCES}

Advani, A., S. Bassi, A. Bowen, S. Frankhauser, P. Johnson, A. Leicester, and G. Stoye, 2013, Energy Use Policies and Carbon Pricing in the UK, Institute for Fiscal Studies Report R84 November.

Advani, A., and G. Stoye, 2017, Cheaper, greened and more efficient: rationalising UK carbon prices. Fiscal Studies, Volume 38, Issue 2, pp. 269-299.

Arregui, N., C. Ebeke, J. Frie, D. Garcia-Macia, D. Iakova, A. Jobst, L. Rabier, J. Roaf, C. Ruo, A. Shabunina, and S. Weber. 2020. "EU Climate Change Mitigation: Sectoral Policies." EUR Departmental Paper, IMF.

Batten, S., 2018. "Climate Change and the Macro-economy: a Critical Review." Bank of England, Working Paper No. 706.

Begh D., and C. Haigh. 2018. "The Unintended Consequences of Freezing Fuel Duty." Greener Journeys, London.

Burke, M., Hsiang, S. M., \& Miguel, E. (2015). Global non-linear effect of temperature on economic production. Nature, 527(7577), 235-239.

Burke J., R. Byrnes, and S. Fankhauser. 2019. "How to Price Carbon to Reach Net-Zero Emissions in the UK." Policy Report, London School of Economics, London.

Chen, J., M. Chepeliev, D. Garcia-Macia, D. Iakova, I. Parry, J. Roaf, A. Shabunina, D. van der Mensbrugghe, and P. Wingender. 2020, "EU Climate Mitigation Policy,” EUR Departmental Paper, IMF.

Coady, D., I. Parry, and B. Shang, 2018. "Energy Price Reform: Lessons for Policymakers." Review of Environmental Economics and Policy 12: 197-219.

Committee on Climate Change (CCC), 2017. "Reducing UK Emissions - 2017.” Progress Report to Parliament, Committee on Climate Change, London.

CCC, 2018. "Reducing UK Emissions - 2018." Progress Report to Parliament, Committee on Climate Change, London.

CCC, 2019. "Reducing UK Emissions - 2019.” Progress Report to Parliament, Committee on Climate Change, London.

CCC, 2020. "Reducing UK Emissions - 2020.” Progress Report to Parliament, Committee on Climate Change, London. 
DBEIS, 2018. Government GHG Conversion Factors for Company Reporting: Methodology paper for emission factors: final report. Department for Business, Energy, and Industrial Strategy.

EC, 2018. Competitiveness of the European Cement and Lime Sectors: Summary of the final report. European Commission, Brussels.

Fearnehough, H., and others, 2018. "Marginal cost of CER supply and implications of demand sources.” Berlin. Available at: https://newclimate.org/wpcontent/uploads/2018/03/Marginal-cost-of-CER-supply.pdf.

Goulder, L. H. and I. Parry, 2008. "Instrument Choice in Environmental Policy.” Review of Environmental Economics and Policy 2: 152-174.

Hirst, D., 2018. Carbon Price Floor (CPF) and Price Support Mechanism. Briefing paper 05927, House of Commons Library, London.

HOC, 2018. Progress on Reducing F-gas Emissions: Fifth Report of Session 2017-19. House of Commons Environmental Audit Committee.

International Monetary Fund (IMF), 2019a. Fiscal Monitor: How to Mitigate Climate Change. International Monetary Fund, Washington, DC.

IMF, 2019b. Fiscal Policies for Paris Climate Strategies-From Principle to Practice. International Monetary Fund, Washington, DC.

IPCC, 2018. Global Warming of $1.5^{\circ} \mathrm{C}$. Intergovernmental Panel on Climate Change, Geneva.

Johnson P., 2016, Carbon Pricing in the United Kingdom, Institute for Fiscal Studies. Available at https://www.ifs.org.uk/publications/8349.

Klenert, D., L. Mattauch, E. Combet, O. Edenhofer, C. Hepburn, R. Rafaty, N. Stern. 2018. Making carbon pricing work for citizens. Nature Climate Change 8, 669-677.

Krupnick, Alan J. and Ian Parry, 2011. "Is a Clean Energy Standard a Good Way to Move U.S. Climate Policy Forward?” Issues Brief, Resources for the Future, Washington DC.

Lenton, T. M., Rockström, J., Gaffney, O., Rahmstorf, S., Richardson, K., Steffen, W., \& Schellnhuber, H. J. (2019). Climate tipping points—-too risky to bet against.

Nordhaus, William, D., 2017. "The Social Cost of Carbon: Updated Estimates.” Proceedings of the US National Academy of Science 114: 518-1,523.

Office for Budget Responsibility (OBR), 2017. Fiscal Risk Report. 
OECD, 2011. Climate Change Policy in the United Kingdom. Organization for Economic Cooperation and Development, Economics Department Working Papers No. 886, Paris, France.

OECD, 2013. Taxing Energy Use. Organization for Economic Cooperation and Development, Paris, France.

OECD, 2017. United Kingdom Economic Survey. Organization for Economic Cooperation and Development, Paris, France.

OECD, 2019. “Taxing Energy Use 2019: Using Taxes for Climate Action.” Organization for Economic Cooperation and Development, Paris, France.

Parry, Ian, 2004. "Comparing Alternative Policies to Reduce Traffic Accidents." Journal of Urban Economics 56: 346-368.

Parry, Ian, 2020. "The Rationale for, and Design of, Forest Carbon Feebates." In, Designing Fiscal Instruments for Sustainable Forests, World Bank Group, forthcoming.

Parry, Ian, Victor Mylonas and Nate Vernon, 2020. "Mitigation Policies for the Paris Agreement: An Assessment for G20 Countries." Journal of the Association of Environment and Resource Economists, forthcoming.

Parry, Ian, Dirk Heine, Kelley Kizzier, and Tristan Smith, 2020. “A Carbon Levy for International Maritime Fuels." Review of Environmental Economics and Policy, forthcoming.

Parry, Ian, Dirk Heine, Shanjun Li, and Elisa Liz, 2014. Getting Energy Prices Right: From Principle to Practice. IMF, Washington, DC.

Rosenow, J., P. Guertler, S. Sorrell, and N. Eyre. 2018. "Remaining potential for energy efficiency in UK homes," Energy Policy.

Schwerhoff, Gregor, 2016. "The Economics of Leadership in Climate Change Mitigation." Climate Policy 16:2, 196-214.

SMMT, 2018. New Car $\mathrm{CO}_{2}$ Report 2018. Society of Motor Manufacturers and Traders.

UK DOT 2018. TAG Data Book. Department for Transport, London. Available at: www.gov.uk/government/publications/tag-data-book.

UN 1992. United Nations Framework Convention on Climate Change. United Nations, New York City, NY.

UNEP, 2019. Emissions Gap Report 2019. UN Environment Programme, Nairobi, Kenya. 
van Ruijven, Bas J. Detlef, P. van Vuuren, Willem Boskaljon, Maarten L. Neelis, Deger Saygin and Martin K. Patel, 2016. "Long-Term Model-Based Projections of Energy Use and CO2 Emissions from the Global Steel and Cement Industries." Resources, Conservation, and Recycling 112, 15.36.

Verdolini, E., Vona, F., and D. Popp, 2018. "Bridging the Gap: Do Fast Reacting Fossil Technologies Facilitate Renewable Energy Diffusion?” Energy Policy 116: 242-256.

WBG, 2020. State and Trends of Carbon Pricing 2020. World Bank Group, Washington, DC.

WEF, 2019. The Global Risks Report 2019. World Economic Forum, Geneva, Switzerland.

Weitzman, Martin L., 2011, "Fat-Tailed Uncertainty in the Economics of Catastrophic Climate Change." Review of Environmental Economics and Policy 5: 275-92.

ZCC, 2020. Zero Carbon Commission on UK Emissions Pricing, Interim Report, June, London. 


\section{ANNEX I: FURTHER DistRibUTIONAL ANALYSIS}

The burden of higher energy prices (implied by more ambitious carbon pricing) would be significantly regressive in the UK, given the relatively high spending of low-income households in natural gas and electricity consumption. Revenue recycling via targeted compensation packages can protect those most vulnerable, while making fiscal space to finance other climate change reforms, cutting distortionary taxes or funding growth-enhancing investments.

\section{This Annex takes a closer look at the distributional implications of addressing the UK carbon pricing gap in domestic energy consumption. As discussed in the main text, the} current policy framework in the UK results in a wide range of carbon effective prices across sectors and users. In particular, a key gap emerges in the residential sector. Carbon price variation could be reduced (and efficiency improved) by extending full-rate VAT to domestic energy use and introducing a tax on domestic gas (Advani and Stoye 2017, OECD 2015). In particular, the analyzed stylized reform consists of:

- The standard VAT rate (20 percent) is applied to domestic energy consumption instead of the reduced rate ( 5 percent), resulting in an increase in natural gas and electricity prices of about 15 percent.

- A new tax on domestic gas consumption is introduced of $£ 21.6 / \mathrm{tCO} 2 \mathrm{e}$ (equivalent to the UK Carbon Price Support that applies to power, including the corresponding standard VAT rate. This results in an increase of natural gas of about 10 percent. ${ }^{1}$

\section{The incidence analysis follows the partial equilibrium approach in Coady and others} (2006), and Fabrizio and others (2016). The simulation uses three data sources obtained from the ONS: the household budget survey, the input-output matrix, and a mapping computed in 2013 from product categories in IO table (CPA) to consumer goods categories in budget surveys (COICOP). The approach relies on multiple assumptions: (i) factor prices are constant, (ii) Leontief production function, where firms' input demand is not affected by changes in input prices, (iii) no changes in production structure (such as from efficiency improvements), and (iv) inelastic consumer behavior. ${ }^{2}$ In line with Advani and Stoye (2017), while the incidence analysis is conducted under the assumption of no behavioral responses (i.e., households continue to consume the same quantity of energy at the new prices), revenues available for redistribution are computed based on reduced energy demand. ${ }^{3}$ These assumptions "tilt the odds" against the

\footnotetext{
${ }^{1}$ For simplicity, the application of VAT on the new natural gas tax is ignored.

${ }^{2}$ Importantly, the analysis does not consider behavioral responses, the impact or funding of energy efficiency investments, nor any potential drop in the production costs for low-carbon electricity. HM Treasury is currently conducting a broad review into the costs of decarbonization, and how these can be shared fairly across the economy.

${ }^{3}$ Taking an elasticity on the low end of the range estimated in the literature (between -0.3 and -0.8 , according to Epsey and Epsey (2004)), an increase in electricity process of 15 percent and an increase in natural gas prices of 25 percent would lead to a reduction in demand (and emissions) of 4.5 and 7.5 percent, respectively. While this is
}

(continued...) 
redistribution exercise. The net impact of the reform across the income distribution is computed as the net of: (i) the additional amount a household would need to purchase a given consumption basket, and (ii) the additional income obtained as part of alternative redistributive packages. The exercise is focused on revenue redistribution and ignores alternative revenue uses that could mitigate the distributional consequences of higher carbon pricing (such as retrofitting).

\section{The impact of higher domestic energy prices would be regressive absent any} compensation. The effect of an energy price increase is in large part determined by the corresponding energy spending share in households' budgets. ${ }^{4}$ While richer households typically spend more on energy in nominal terms, poorer households tend to spend relatively more as a fraction of their income or total consumption. The average energy spending in proportion to total consumption is three times as large for households in the bottom quintile of the income distribution relative to those in the upper quintile. As a result, in the absence of compensation scheme, the impact of the tax reform would be regressive. The median loss for households in the bottom quintile would amount to about 1.7 percent of total expenditure, while it would amount to 0.6 for those in the top quintile. ${ }^{5}$ Within quintile variation is significant, in particular at the bottom quintile. While the analysis in the rest of this annex is focused on distributional issues along the consumption distribution, it should be noted that:

- The impact is more regressive when measured on an income basis (instead of a consumption basis), as richer households tend to consume a smaller share of their income.

- Governments typically show concern about the "horizontal" implications of policies (that is, treating individuals of a similar income level too differently based on other characteristics) which could be important for the political acceptability of a reform. For instance, rural households are more likely to be connected only to the electricity grid than urban households, resulting in significantly different patterns of energy consumption. ${ }^{6}$

only a fraction of what is needed to achieve residential full decarbonization, this is significant when compared to the historical progress achieved since 1990.

${ }^{4}$ The elimination of the VAT reduced rate is modeled as a direct impact (i.e., percent price increase times budget share). The introduction of a new tax on natural gas has both an analogous direct impact, as well as an indirect impact (stemming from the effect of higher natural gas prices on the production costs of other non-energy goods and services). In the latter case, the indirect effect tends to be dominated by direct effect.

${ }^{5}$ Richer households lose more in nominal terms but are less affected in proportion to their total expenditure.

${ }^{6}$ In the sample, about one third of rural households are not connected to the gas grid, compared to about ten percent for urban households. 


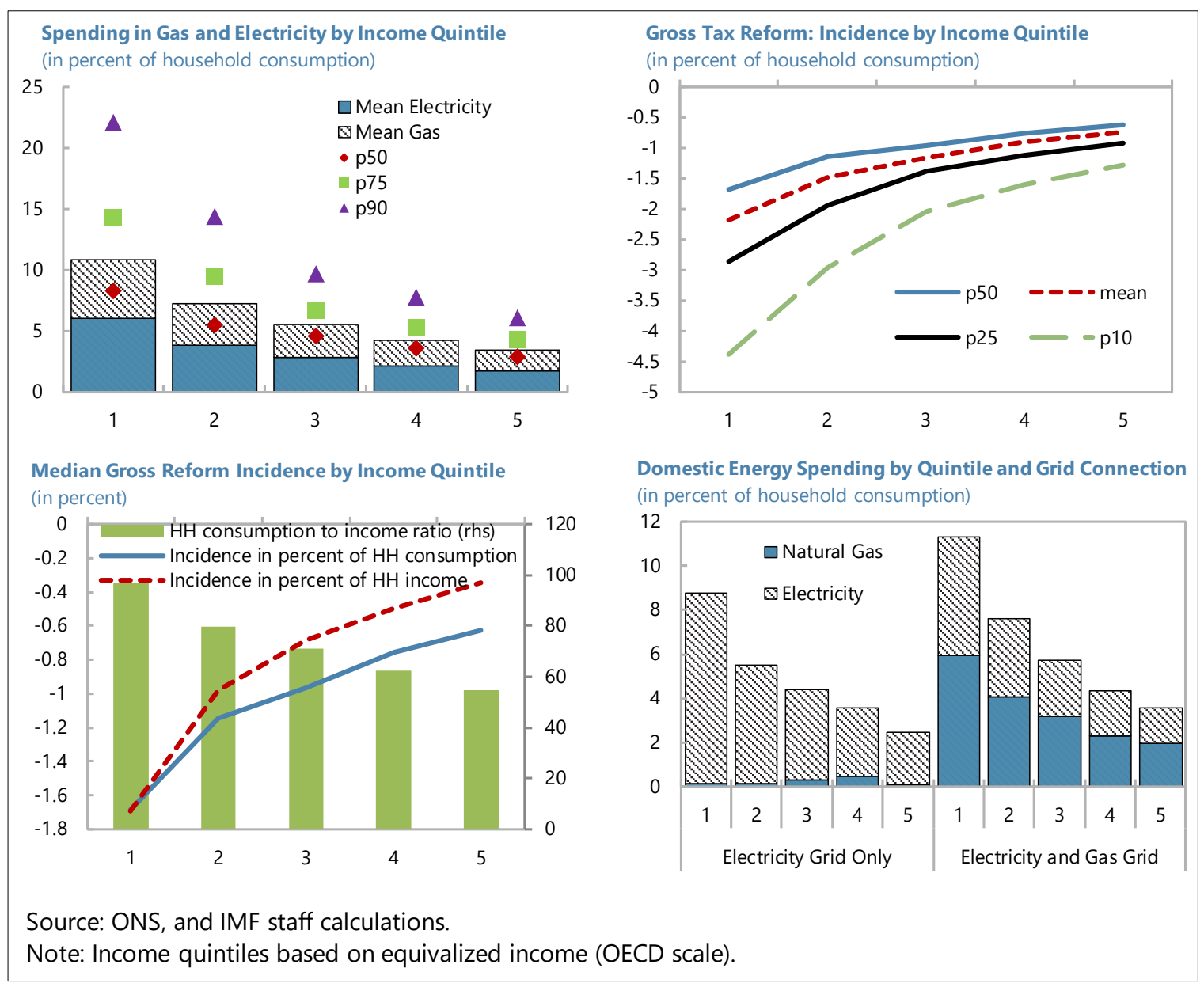

\section{A lump-sum compensation package would be poorly targeted and would not enhance economic efficiency. A simple compensation} package could distribute revenues equally across all households. ${ }^{7}$ Lump sum revenue recycling appears to do a good job, on average, in offsetting the regressive tax reform: the mean or median household across different quintiles fares a relatively similar net cost in proportion of total consumption (about 0.35 percent). ${ }^{8}$ However, focusing on average or median impact masks the

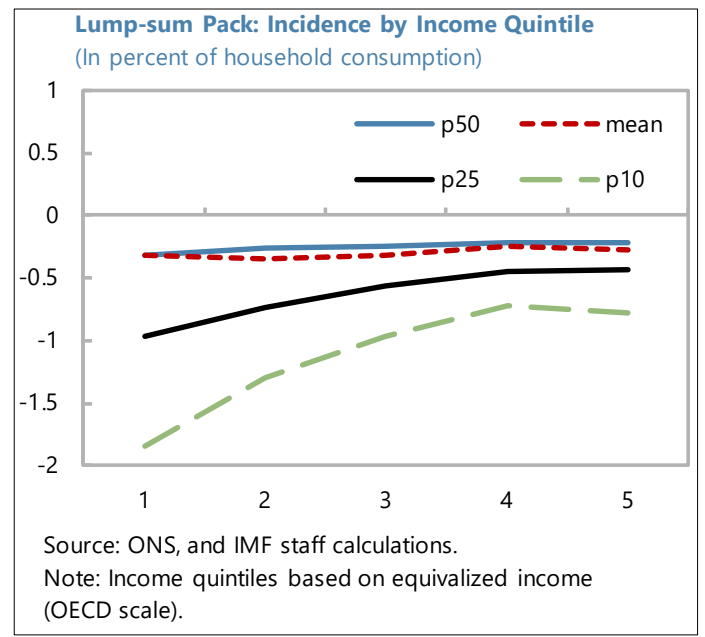

\footnotetext{
${ }^{7}$ Universal lump sum compensation packages are typically defended more on political economy than on economic efficiency grounds (as they divert a large amount of revenue from more productive uses). For instance, in the US context, the Climate Leadership Council (2017) advocates that all revenues of a rising carbon tax should be returned to the citizens through equal lump-sum rebates, "to maximize the fairness and political viability" of the reform.

${ }^{8}$ The lump-sum package would actually make net-incidence progressive if behavioral responses were not assumed to reduce total revenues available for redistribution.
} 
significantly heterogeneous impact across households: losses would remain significant for some households, particularly at the bottom of the income distribution.

More targeted compensation packages can protect those most vulnerable, while making fiscal space to finance other climate change reforms, cutting distortionary taxes or funding growth-enhancing investments. Instead of a universal lump- sum package, the government could choose to exclude richer households from any compensation, making more resources available to mitigate the losses incurred by those at the bottom of the income distribution. For illustration purposes, two compensation packages are considered: (a) doubling the nominal lump sum amount for those in the bottom quintiles of the distribution, and (b) doubling the lump sum amount for those in the bottom quintiles that are considered "vulnerable households."

Vulnerable households are defined as those including pensioner or disabled members, and those receiving income support and/or where the reference person is unemployed (see regression analysis below). Both packages improve the outcomes of those at the bottom of the distribution. The first package does so to a larger extent, and arguably goes above and beyond the objective of mitigating the negative consequences of the reform. The second package is more limited, and is funded using just about 60 percent of the total revenue collected, leaving fiscal room for additional policies. To maximize economic efficiency, revenue should be used to decrease (or to avoid the need to raise) distortionary taxes such as the labor income tax, or to address critical public investment gaps (see Chen and others, forthcoming). ${ }^{9}$

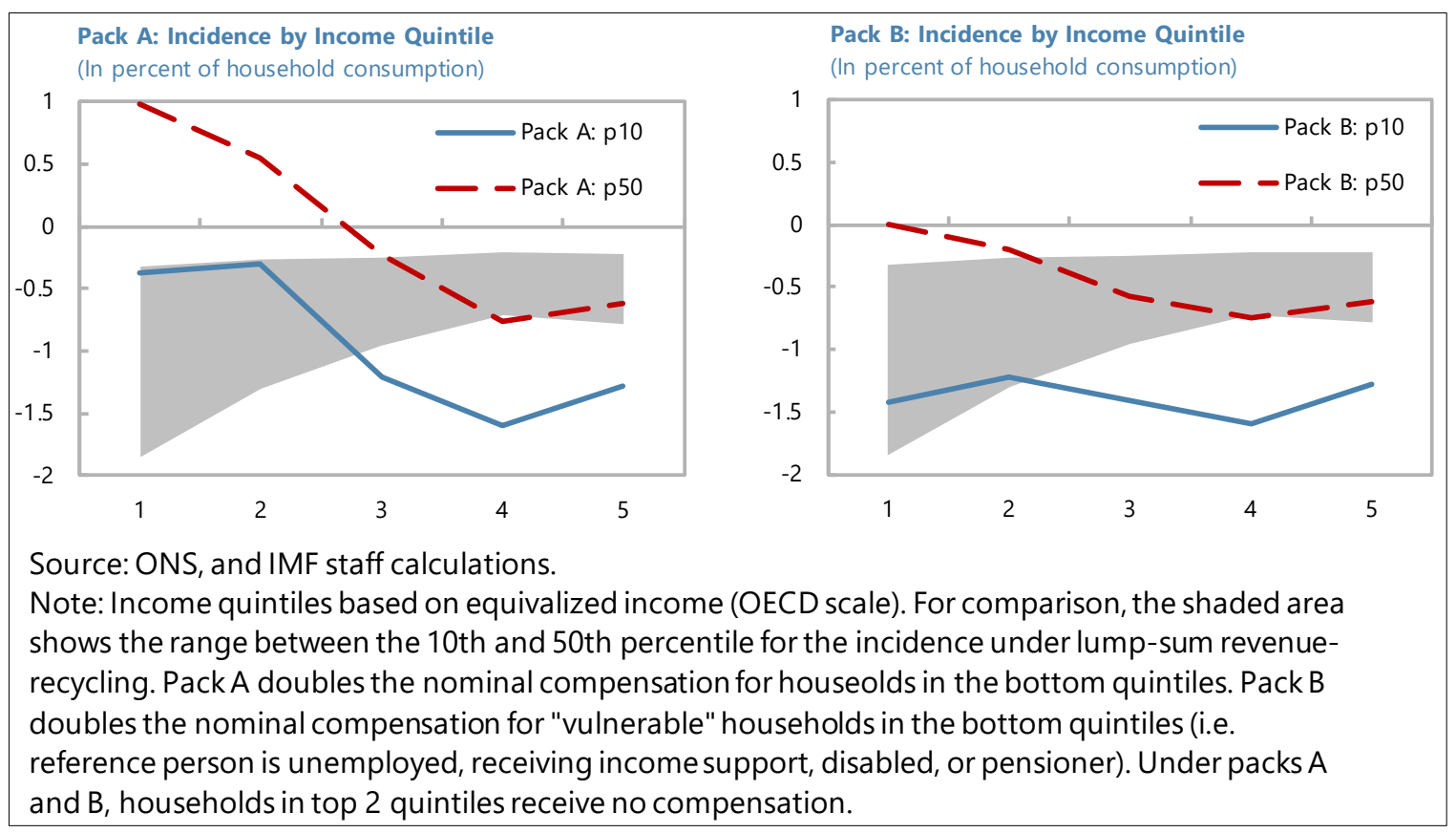

\footnotetext{
${ }^{9}$ According to the authors' estimations, using carbon pricing revenue to cut labor taxes would recoup almost all income losses from higher carbon prices. This is because with high initial labor tax rates and unemployment rates, labor taxes are roughly as distortionary as carbon taxes.
} 
Share of $\mathrm{HH}$ total spending in...

\begin{tabular}{|c|c|c|c|c|c|c|c|c|c|c|c|c|}
\hline & \multicolumn{12}{|c|}{ Share of $\mathrm{HH}$ total spending in... } \\
\hline & NatGas \& Elec & NatGas & Elec & NatGas \& Elec & NatGas & Elec & NatGas \& Elec & NatGas & Elec & NatGas \& Elec & NatGas & Elec \\
\hline D: Dwelling dettached or semi-detacched? Yes $=1$ & $\begin{array}{c}0.138 \\
(0.406)\end{array}$ & $\begin{array}{c}0.272^{* * *} \\
(0.004)\end{array}$ & $\begin{array}{l}-0.134 \\
(0.199)\end{array}$ & $\begin{array}{c}0.061 \\
(0.718)\end{array}$ & $\begin{array}{c}0.245^{* * *} \\
(0.009)\end{array}$ & $\begin{array}{l}-0.184^{*} \\
(0.080)\end{array}$ & $\begin{array}{c}0.109 \\
(0.514)\end{array}$ & $\begin{array}{c}0.250 * * * \\
(0.008)\end{array}$ & $\begin{array}{l}-0.141 \\
(0.179)\end{array}$ & $\begin{array}{c}0.030 \\
(0.861)\end{array}$ & $\begin{array}{c}0.224^{* *} \\
(0.018)\end{array}$ & $\begin{array}{l}-0.195^{*} \\
(0.066)\end{array}$ \\
\hline Number of rooms in accomodation & $\begin{array}{c}0.126 \\
(0.328)\end{array}$ & $\begin{array}{c}0.117 \\
(0.107)\end{array}$ & $\begin{array}{c}0.009 \\
(0.916)\end{array}$ & $\begin{array}{c}0.039 \\
(0.764)\end{array}$ & $\begin{array}{c}0.090 \\
(0.215)\end{array}$ & $\begin{array}{l}-0.052 \\
(0.528)\end{array}$ & $\begin{array}{c}0.133 \\
(0.305)\end{array}$ & $\begin{array}{l}0.124^{*} \\
(0.091)\end{array}$ & $\begin{array}{c}0.009 \\
(0.910)\end{array}$ & $\begin{array}{c}0.084 \\
(0.519)\end{array}$ & $\begin{array}{c}0.110 \\
(0.135)\end{array}$ & $\begin{array}{c}-0.025 \\
(0.757)\end{array}$ \\
\hline D: Accomodation supplied with Gas and Elec? Yes $=1$ ( $0=$ Elec only) & $\begin{array}{c}1.673 * * * \\
(0.000)\end{array}$ & $\begin{array}{c}3.580 * * * \\
(0.000)\end{array}$ & $\begin{array}{c}-1.907 * * * \\
(0.000)\end{array}$ & $\begin{array}{c}1.695 * * * \\
(0.000)\end{array}$ & $\begin{array}{c}3.588 * * * \\
(0.000)\end{array}$ & $\begin{array}{c}-1.893 * * * \\
(0.000)\end{array}$ & $\begin{array}{c}1.608 * * * \\
(0.000)\end{array}$ & $\begin{array}{c}3.549 * * * \\
(0.000)\end{array}$ & $\begin{array}{c}-1.941 * * * \\
(0.000)\end{array}$ & $\begin{array}{c}1.688 * * * \\
(0.000)\end{array}$ & $\begin{array}{c}3.585^{* * * *} \\
(0.000)\end{array}$ & $\begin{array}{c}-1.897^{* * *} \\
(0.000)\end{array}$ \\
\hline HH Size & $\begin{array}{c}-0.849 * * * \\
(0.000)\end{array}$ & $\begin{array}{c}-0.467^{* * *} \\
(0.000)\end{array}$ & $\begin{array}{c}-0.383^{* * *} \\
(0.000)\end{array}$ & $\begin{array}{c}-0.854^{* * * *} \\
(0.000)\end{array}$ & $\begin{array}{c}-0.466 * * * \\
(0.000)\end{array}$ & $\begin{array}{c}-0.388^{* * *} \\
(0.000)\end{array}$ & $\begin{array}{c}-0.879 * * * \\
(0.000)\end{array}$ & $\begin{array}{c}-0.474^{* * *} \\
(0.000)\end{array}$ & $\begin{array}{c}-0.406^{* * *} \\
(0.000)\end{array}$ & $\begin{array}{c}-0.880 * * * \\
(0.000)\end{array}$ & $\begin{array}{c}-0.476^{* * *} \\
(0.000)\end{array}$ & $\begin{array}{c}-0.404^{* * *} \\
(0.000)\end{array}$ \\
\hline D: Pensioner in $\mathrm{HH}$ ? Yes=1 & $1.342^{* * *}$ & $0.895^{* * *}$ & $0.447^{*}$ & $1.443^{* * *}$ & $0.939 * * *$ & $0.504^{* *}$ & $2.009 * * *$ & $1.213^{* * *}$ & $0.796 * * *$ & $2.095^{* * *}$ & $1.216^{* * *}$ & $0.878^{* * *}$ \\
\hline & $(0.000)$ & $(0.000)$ & $(0.061)$ & $(0.000)$ & $(0.000)$ & $(0.037)$ & $(0.000)$ & $(0.000)$ & $(0.001)$ & $(0.000)$ & $(0.000)$ & $(0.000)$ \\
\hline D: Reference person in $\mathrm{HH}$ is unemployed? Yes $=1$ & $1.995 * * *$ & 0.351 & $1.644^{* * *}$ & $2.493 * * *$ & 0.511 & $1.981^{* * *}$ & $2.068^{* * *}$ & 0.329 & $1.739 * * *$ & $2.739 * * *$ & $0.594^{*}$ & $2.145^{* * *}$ \\
\hline D: Disabled in HH? Yes=1 & $\begin{array}{c}(0.000) \\
1.816^{* * *}\end{array}$ & $\begin{array}{c}(0.262) \\
0.850^{* * *}\end{array}$ & $\begin{array}{c}(0.000) \\
0.966^{* * *}\end{array}$ & $\begin{array}{c}(0.000) \\
1.807 * * *\end{array}$ & $\begin{array}{c}(0.102) \\
0.858^{* * *}\end{array}$ & $\begin{array}{c}(0.000) \\
0.949 * * *\end{array}$ & $\begin{array}{c}(0.000) \\
1.895 * * *\end{array}$ & $\begin{array}{c}(0.294) \\
0.924^{* * *}\end{array}$ & $\begin{array}{c}(0.000) \\
0.970 * * *\end{array}$ & $\begin{array}{c}(0.000) \\
1.820^{* * *}\end{array}$ & $\begin{array}{c}(0.057) \\
0.882 * * *\end{array}$ & $\begin{array}{c}(0.000) \\
0.938^{* * *}\end{array}$ \\
\hline & $(0.001)$ & $(0.006)$ & $(0.005)$ & $(0.001)$ & $(0.006)$ & $(0.006)$ & $(0.001)$ & $(0.003)$ & $(0.005)$ & $(0.001)$ & $(0.005)$ & $(0.007)$ \\
\hline D: HH receives income support? Yes $=1$ & $4.121 * * *$ & $1.808^{* * *}$ & $2.314^{* * *}$ & $4.532 * * *$ & $1.931^{* * *}$ & $2.602 * * *$ & $4.757^{* * *}$ & $2.038^{* * *}$ & $2.719 * * *$ & $5.024 * * *$ & $2.127 * * *$ & $2.897 * * *$ \\
\hline & $(0.000)$ & $(0.000)$ & $(0.000)$ & $(0.000)$ & $(0.000)$ & $(0.000)$ & $(0.000)$ & $(0.000)$ & $(0.000)$ & $(0.000)$ & $(0.000)$ & $(0.000)$ \\
\hline Eq. Income Dummies by & Decile & Decile & Decile & Quintile & Quintile & Quintile & & & & & & \\
\hline $\log ($ Eq. Inc.) & & & & & & & $\begin{array}{c}-3.910 * * * \\
(0.000)\end{array}$ & $\begin{array}{c}-1.716^{* * *} \\
(0.000)\end{array}$ & $\begin{array}{c}-2.194^{* * *} \\
(0.000)\end{array}$ & & & \\
\hline Eq. Inc. & & & & & & & & & & $\begin{array}{c}-0.018^{* * *} \\
(0.000)\end{array}$ & $\begin{array}{c}-0.008^{* * *} \\
(0.000)\end{array}$ & $\begin{array}{c}-0.010^{* * *} \\
(0.000)\end{array}$ \\
\hline Eq. Inc. Squared & & & & & & & & & & $\begin{array}{c}0.000 * * * \\
(0.000)\end{array}$ & $\begin{array}{c}0.000 * * * \\
(0.000)\end{array}$ & $\begin{array}{c}0.000^{* * *} \\
(0.000)\end{array}$ \\
\hline Constant & $\begin{array}{c}12.380^{* * *} \\
(0.000)\end{array}$ & $\begin{array}{c}2.899 * * * \\
(0.000)\end{array}$ & $\begin{array}{c}9.481^{* * *} \\
(0.000)\end{array}$ & $\begin{array}{c}11.278^{* * *} \\
(0.000)\end{array}$ & $\begin{array}{c}2.589 * * * \\
(0.000)\end{array}$ & $\begin{array}{c}8.689 * * * \\
(0.000)\end{array}$ & $\begin{array}{c}29.542^{* * *} \\
(0.000)\end{array}$ & $\begin{array}{c}10.660 * * * \\
(0.000)\end{array}$ & $\begin{array}{c}18.882^{* * *} \\
(0.000)\end{array}$ & $\begin{array}{c}12.395 * * * \\
(0.000)\end{array}$ & $\begin{array}{c}3.169 * * * \\
(0.000)\end{array}$ & $\begin{array}{c}9.226 * * * \\
(0.000)\end{array}$ \\
\hline Regional Dummies & YES & YES & YES & YES & YES & YES & YES & YES & YES & YES & YES & YES \\
\hline Observations & 4,580 & 4,580 & 4,580 & 4,580 & 4,580 & 4,580 & 4,580 & 4,580 & 4,580 & 4,580 & 4,580 & 4,580 \\
\hline R-squared & 0.299 & 0.303 & 0.290 & 0.283 & 0.297 & 0.270 & 0.287 & 0.294 & 0.279 & 0.275 & 0.292 & 0.264 \\
\hline $\begin{array}{l}\text { pval in parentheses } \\
*_{* * *} p<0.01, * * p<0.05, * p<0.1\end{array}$ & & & & & & & & & & & & \\
\hline tait calculations. & & & & & & & & & & & & \\
\hline
\end{tabular}

